- Article type: paper (3000-5000 words with one illustration per 500 words).

- $9^{\text {th }}$ December 2014

- 5183,15 .

\title{
Improving the lateral capacity of monopiles in submarine clay
}

\section{Author 1}

- Aliasger Haiderali, PhD, CEng MICE

- Department of Engineering, University of Cambridge, Cambridge, UK

Author 2

- Gopal Madabhushi, PhD

- Professor of Civil Engineering, Department of Engineering, University of Cambridge, Cambridge, UK

\section{Full contact details of corresponding author.}

Schofield Centre, Department of Engineering, University of Cambridge, High Cross, Madingley Road, Cambridge CB3 0EL

Tel: 07969673019

Email: aliasger.haiderali@gmail.com 


\section{Abstract (166 words)}

The European offshore wind sector has been undergoing tremendous growth resulting in offshore wind farms having larger wind turbines that are located further away from the shore in harsh environmental conditions. To cater for the resulting higher loads, the current trend has been to continually increase the size of monopiles, which are the most popular foundation type. However, this is not viable long-term in terms of current installation technology.

This paper presents the results of three dimensional finite element analyses investigating the improvement in the lateral capacity of a large diameter monopile in clay when used in combination with hybrid features and rock armour. Non-skirted reinforced concrete and steel footings, a skirted steel footing and steel fins were assessed under a combination of vertical, lateral and moment loads expected at an offshore wind farm location with a water depth of 30 $\mathrm{m}$.

Findings, based on shear and bending moment developed in the monopile and mobilised soil resistance, indicated the skirted steel footing and fins to be the most effective in enhancing the monopile lateral capacity at serviceability.

\section{Keywords chosen from ICE Publishing list}

Geotechnical engineering; Offshore engineering; Piles \& piling

\section{List of notation}

$c^{\prime} \quad$ is the cohesion intercept

$C_{c} \quad$ is the compression index

$C_{s} \quad$ is the swelling index

$C_{p} \quad$ is a constant used in computing the saturated permeability for clays

$C_{u} \quad$ is a coefficient of uniformity

$d \quad$ is the material cohesion for the Modified Drucker-Prager model

$d_{10} \quad$ is the grain diameter for which $10 \%$ of the sample is finer

$D \quad$ is the outer pile diameter

$e_{0} \quad$ is the initial void ratio

$E \quad$ is the undrained Young's modulus of soil

$E^{\prime} \quad$ is the drained Young's modulus of soil

$E_{50}^{\prime}$ is the secant modulus corresponding to a stress level of $50 \%$ of the peak strength

$E_{\text {ref }} \quad$ is the reference Young's modulus

$E_{0} \quad$ is the Young's modulus of concrete

$F \quad$ is the monopile shear force

$F_{c} \quad$ is the cap yield surface for the Modified Drucker-Prager model

$F_{S} \quad$ is the shear failure surface for the Modified Drucker-Prager model 
$h_{w} \quad$ is the water depth

$G_{S} \quad$ is the specific gravity

$H \quad$ is the lateral load applied to the monopile

$H_{\text {serv }} \quad$ is the lateral pile capacity at serviceability

$k_{\text {sat }} \quad$ is the saturated permeability of clay

$K_{0} \quad$ is the coefficient of earth pressure at rest

$L \quad$ is the embedded pile length

$L_{T} \quad$ is the total pile length

$M \quad$ is the monopile bending moment

$M_{a} \quad$ is the overturning moment at mudline

$M_{p} \quad$ is the plastic moment

$M_{y} \quad$ is the yield moment

$O C R$ is the over-consolidation ratio

$p \quad$ is the soil resistance against the pile

$p^{\prime} \quad$ is the mean effective stress

$p_{a} \quad$ is a parameter that controls the volumetric plastic strain driven hardening/softening

$p_{b} \quad$ is the mean pre-consolidation stress

$p_{h} \quad$ is the mean equivalent hydrostatic stress

$p_{\text {ref }} \quad$ is the atmospheric pressure

$P I \quad$ is the plasticity index

$R \quad$ is the cap eccentricity for the Modified Drucker-Prager model

$s_{u} \quad$ is the undrained shear strength

$t \quad$ is the deviatoric stress

$t_{\text {fin }} \quad$ is the fin thickness

$t_{p} \quad$ is the pile wall thickness

$V \quad$ is the axial load applied to the monopile

$w_{L} \quad$ is the liquid limit

$x \quad$ is the tortuosity parameter used in computing the saturated permeability for clays

$y \quad$ is the lateral pile displacement

$y_{a} \quad$ is the lateral displacement applied at the pile head

$y_{m} \quad$ is the lateral pile displacement at mudline

$z \quad$ is the depth below mudline

$\gamma_{\text {sat }} \quad$ is the saturated unit weight of soil

$\gamma_{w} \quad$ is the unit weight of water

$\rho_{s} \quad$ is the density of solid grains

$\theta_{m} \quad$ is the pile head rotation at mudline

$\varphi^{\prime} \quad$ is the angle of friction

$\varphi_{c s}^{\prime} \quad$ is the critical state friction angle

$\varphi_{p}^{\prime} \quad$ is the peak friction angle 
$\delta \quad$ is the pile-soil interface friction angle

$\alpha \quad$ is the radius of the transition surface

$\beta \quad$ is the angle of friction for the Modified Drucker-Prager model

$\sigma_{c}^{\prime} \quad$ is the vertical pre-consolidation stress

$\sigma_{x}^{\prime} \quad$ is the effective lateral stress

$\mu_{w} \quad$ is the dynamic viscosity of water

$\chi \quad$ is a material parameter used in computing the saturated permeability for clays

$v^{\prime} \quad$ is the drained Poisson's ratio

$\psi \quad$ is the dilatancy angle

$\varepsilon_{\text {vol }}^{\mathrm{p}} \quad$ is the volumetric plastic strain 


\section{Introduction}

The offshore wind sector in the European Union is undergoing phenomenal growth with forecasts indicating its installed capacity in the year 2020 to be $40 \mathrm{GW}$, representing an eightfold increase from its current capacity of 5 GW (EWEA 2013). Owing to their ease of fabrication and installation, monopiles are currently the most popular type of foundation for supporting offshore wind turbines in shallow to medium depth waters of up to $30 \mathrm{~m}$. Monopiles are driven open-ended tubular steel piles, 4-6 $\mathrm{m}$ in diameter with an embedded length to diameter ratio of 4-8. With offshore wind farms increasingly being located further away from the shore and wind turbines increasing in size, larger monopiles are being required to withstand the corresponding structural and environmental loads. However, they would be impractical to install using current offshore technology. Therefore, it is vital that an improvement in monopile lateral capacity is investigated using hybrid features that are feasible to construct and install.

Centrifuge tests and three-dimensional (3D) finite element analyses (FEA) by Lehane et al. 2014 indicated that, at prototype scale, a steel footing, $17.5 \mathrm{~m}$ in diameter and $2.625 \mathrm{~m}$ in thickness, when used in combination with a 3.33 m diameter monopile in sand, led to almost a doubling of the lateral pile capacity. Similarly, centrifuge tests by Stone et al. 2011 on a $0.95 \mathrm{~m}$ diameter pile combined with a steel footing, $5 \mathrm{~m}$ in diameter and $0.25 \mathrm{~m}$ in thickness, also reported an increase in the lateral pile capacity in sand. $1 \mathrm{~g}$ model tests by Arshi et al. 2013 indicated that the addition of skirts to $80 \mathrm{~mm}$ diameter steel footings increased the lateral pile capacity in sand by approximately $50 \%$ relative to the non-skirted footings. However, there were ambiguities in the reported results as skirt lengths were not specified. On the contrary, centrifuge tests and 3D FEA by Lehane et al. 2010 suggested that $15-20 \mathrm{~m}$ diameter footings, both non-skirted and skirted, were ineffective in increasing the lateral capacity of a $4 \mathrm{~m}$ diameter monopile in clay with a near surface undrained shear strength of $20 \mathrm{kPa}$.

Bienen et al. 2012 showed through centrifuge tests in medium dense sand that the lateral capacity of a prototype pile, $2.4 \mathrm{~m}$ in diameter and $9.6 \mathrm{~m}$ in embedded length, was increased by $40 \%$ when it was used in combination with steel fins, $3.2 \mathrm{~m}$ in length and $1.6 \mathrm{~m}$ in width. $1 \mathrm{~g}$ 
model tests and 3D FEA by Peng et al. 2010 indicated the optimum fin length for a short rigid pile in medium dense sand to be half the embedded pile length. Through $1 g$ tests on flexible piles with embedded length to diameter ratio of 15, Nasr 2014 reported that in comparison to triangular fins, rectangular fins were more effective in increasing the lateral pile capacity in medium dense sand. Bienen et al. 2012 and Nasr 2014 used 2 fins perpendicular to the direction of lateral loading whereas Peng et al. 2010 employed 4 equally spaced fins.

Although they indicate promising results, with the exception of Lehane et al. 2010, all these studies have been undertaken in sand. However, geotechnical investigation reports for offshore wind farms in the Irish Sea and the United Kingdom sector of the North Sea indicate significant presence of clays within the seabed. In addition, a detailed study comparing the various hybrid options in clayey soils using realistic prototype dimensions applicable to monopiles whilst incorporating varied construction materials such as steel, reinforced concrete (RC) and rock, has yet to be undertaken.

To plug this research gap, 3D soil-pore fluid coupled FEA was undertaken using Abaqus/Standard Version 6.12 (Dassault Systèmes 2012) to analyse the improvement in the lateral capacity of a $5 \mathrm{~m}$ diameter monopile in clay when used in combination with rock armour, non-skirted RC and steel footings, skirted steel footing and steel fins.

\section{Model geometry}

\subsection{Monopile}

Based on statistics of installed monopiles (LORC 2011), the monopile was modelled to have an outer diameter, $D$, of $5 \mathrm{~m}$, wall thickness, $t_{p}$, of $60 \mathrm{~mm}$, total length, $L_{T}$, of $66 \mathrm{~m}$ and embedded length, $L$, of $30 \mathrm{~m}$.

\subsection{Soil}

The soil block was cylindrical with a diameter of $100 \mathrm{~m}(20 \mathrm{D})$ and a height of $50 \mathrm{~m}(1.67 \mathrm{~L})$. These dimensions were verified to be adequate in preventing artificial boundary effects on the behaviour of the hybrid monopile-soil system. The bottom of the soil was fixed against 


\subsection{Hybrid features}

The footing diameter and fin length were based on previous research on hybrid monopiles, in which the former was between 3.75 and 5.3D (Lehane et al. 2010, Lehane et al. 2014, Stone et al. 2011) and the latter was considered optimum at $0.5 \mathrm{~L}$ (Peng et al. 2010). However, to facilitate the installation of the finned monopile in practice, the fin width adopted was between 20-40\% smaller than used in past research (Peng et al. 2010, Bienen et al. 2012). The thickness of the footings, skirt and fins was dictated by constructability whereas the skirt length was based on available field data for suction caissons (Houlsby et al. 2005).

\subsubsection{RC footing}

The circular RC footing was an annulus that was $1 \mathrm{~m}$ thick with an outer diameter of $20 \mathrm{~m}(4 \mathrm{D})$ through which there was a $5 \mathrm{~m}$ diameter opening for the pile. A sectional view of this footing is shown in Figure 1a. Assuming the footing would be grouted to the monopile, the pile-footing interface was governed by tangential and normal contact constraints. A conservative value of 0.1 was used for the coefficient of friction between wet steel and concrete (Gorst et al. 2003). To control cracking in the footing, $32 \mathrm{~mm}$ diameter steel reinforcing bars were used. The area of reinforcement provided was $0.21 \%$ of the cross-sectional area of the footing, which conformed to the minimum tensile reinforcement requirements of Eurocode 2 (BSI 2004).

\subsubsection{Steel footing}

The circular steel footing was $0.15 \mathrm{~m}$ thick with a diameter of $20 \mathrm{~m}(4 D)$ through which there was a $5 \mathrm{~m}$ diameter opening for the pile. Since the footing would be welded to the monopile, its translation and rotation were constrained to the monopile segment. A cross-sectional view is shown in Figure $1 b$.

\subsubsection{Skirted steel footing}

Illustrated in Figure 1c, its dimensions were the same as the steel footing except that it had a skirt, $5 \mathrm{~m}$ in length and $0.06 \mathrm{~m}$ in thickness. 


\subsubsection{Steel fins}

The monopile geometry was altered to provide it with 4 rectangular fins, each having length of $15 \mathrm{~m}(0.5 \mathrm{~L})$, width of $2 \mathrm{~m}(0.4 \mathrm{D})$ and thickness, $t_{\mathrm{fin}}$, of $0.06 \mathrm{~m}$. Although the unidirectional lateral load used in these analyses only required 2 fins that were perpendicular to the direction of loading, 4 equally spaced fins were used in the model to cater for the multi-directional loading scenario that would exist at an offshore wind farm location. Its sectional view is shown in Figure $1 d$.

With the exception of reinforcing bars for which 2-noded linear truss elements (T3D2) were employed, 8-noded linear elements were used for the rest of the components. Quadratic elements were not used as they brought about a negligible increase in accuracy at a considerable computational cost (Haiderali 2015). The monopile, skirted and non-skirted steel footings, and fins were constructed of reduced integration continuum shell elements (SC8R) whereas the RC footings and the soil were made of full integration brick elements with the latter having pore pressure degree of freedom (C3D8 and C3D8P respectively). Relatively fine meshes comprising 143,840 to 144,160 elements (depending on the hybrid feature) were verified to be sufficiently accurate via a mesh sensitivity study (Haiderali 2015). The monopile$\mathrm{RC}$ footing-soil meshed model and a close-up view of the monopile-skirted footing-soil model, is illustrated in Figure 2. For clarity, only one-half of the model, along the axis of load symmetry, is shown.

\section{Material models}

A ground investigation factual report for a proposed offshore wind farm in the English Channel was used to develop the soil model comprising $1 \mathrm{~m}$ of soft clay underlain by $9 \mathrm{~m}$ of stiff clay, 20 $\mathrm{m}$ of very stiff clay and $20 \mathrm{~m}$ of very dense sand. The soil profile is illustrated in Figure 2. All soils were considered to be fully saturated, their key geotechnical parameters summarised in Table 1. Due to the permeability of the clay being very low relative to the rate of loading, these analyses simulated undrained conditions as would occur in practice under an extreme storm. 
Table 1 Key geotechnical parameters

\begin{tabular}{|c|c|c|}
\hline Depth & Soil type & Parameters \\
\hline $0-1 \mathrm{~m}$ & Soft clay & $\begin{array}{l}G_{\mathrm{s}}=2.61, \gamma_{\mathrm{sat}}=15.51-17.05 \mathrm{kN} / \mathrm{m}^{3} \\
w_{\mathrm{L}}=78 \%, w_{\mathrm{P}}=21 \%, P I=57 \% \\
C_{\mathrm{c}}=0.575, C_{\mathrm{s}}=0.115 \\
\varphi_{c s}^{\prime}=19.7^{\circ}, \mathrm{c}^{\prime}=0.5 \mathrm{kPa}\left(\beta=37.2^{\circ}, d=1.1 \mathrm{kPa}\right) \\
K_{0}=0.663, \delta=15.9^{\circ}, \mu=0.285, v^{\prime}=0.3 \\
k_{\mathrm{sat}}=7.94 \times 10^{-10}-2.02 \times 10^{-10} \mathrm{~m} / \mathrm{s}\end{array}$ \\
\hline $1-10 m$ & Stiff clay & $\begin{array}{l}G_{\mathrm{s}}=2.73, \gamma_{\mathrm{sat}}=20.10-21.65 \mathrm{kN} / \mathrm{m}^{3} \\
w_{\mathrm{L}}=67 \%, w_{\mathrm{P}}=23 \%, P I=44 \% \\
C_{\mathrm{c}}=0.329, C_{\mathrm{s}}=0.063 \\
\varphi_{\mathrm{p}}^{\prime}=21^{\circ}, \mathrm{c}^{\prime}=10.6-19.4 \mathrm{kPa}\left(\beta=39.1^{\circ}, d=22.4-41.2 \mathrm{kPa}\right) \\
K_{0}=1.673-0.895, \delta=16.5^{\circ}, \mu=0.296, v^{\prime}=0.25 \\
k_{\mathrm{sat}}=3.56 \times 10^{-11}-8.5 \times 10^{-12} \mathrm{~m} / \mathrm{s}\end{array}$ \\
\hline $10-30 m$ & $\begin{array}{l}\text { Very stiff } \\
\text { clay }\end{array}$ & $\begin{array}{l}G_{\mathrm{s}}=2.73, \gamma_{\mathrm{sat}}=21.65-22.32 \mathrm{kN} / \mathrm{m}^{3} \\
w_{\mathrm{L}}=63.3 \%, w_{\mathrm{P}}=22.4 \%, P I=40.9 \% \\
C_{\mathrm{c}}=0.170, C_{\mathrm{s}}=0.022 \\
\varphi_{\mathrm{p}}^{\prime}=21.4^{\circ}, \mathrm{c}^{\prime}=20 \mathrm{kPa}\left(\beta=39.8^{\circ}, d=42.4 \mathrm{kPa}\right) \\
K_{0}=0.891-0.657, \delta=16.7^{\circ}, \mu=0.3, v^{\prime}=0.25 \\
k_{\text {sat }}=9.82 \times 10^{-12}-4.87 \times 10^{-12} \mathrm{~m} / \mathrm{s}\end{array}$ \\
\hline $30-50 m$ & $\begin{array}{l}\text { Very dense } \\
\text { sand }\end{array}$ & $\begin{array}{l}G_{\mathrm{s}}=2.65, \gamma_{\mathrm{sat}}=20.98 \mathrm{kN} / \mathrm{m}^{3} \\
d_{10}=0.023 \mathrm{~mm}, C_{\mathrm{u}}=3.91 \\
\varphi_{\mathrm{p}}^{\prime}=33^{\circ}, \mathrm{c}^{\prime}=0.5 \mathrm{kPa}, \Psi=5^{\circ} \\
K_{0}=0.455, \delta=23.1^{\circ}, \mu=0.427, v^{\prime}=0.35 \\
k_{\text {sat }}=9.74 \times 10^{-6} \mathrm{~m} / \mathrm{s}\end{array}$ \\
\hline
\end{tabular}

\subsection{Clay}

As shown in Figure 3a, the soft normally consolidated clay had undrained shear strength, $s_{u}$, of $25 \mathrm{kPa}$ while the stiff and very stiff over-consolidated clays had $s_{u}$ of $100-200 \mathrm{kPa}$ and 200-350 $\mathrm{kPa}$ respectively. With the exception of soft clay, for which it was zero, the cohesion intercept, $c^{\prime}$, was assumed to be $10 \%$ of $s_{u}$ (Danish Standards 1998). However, its maximum value was capped at $10 \mathrm{kPa}$ for the stiff clay and $20 \mathrm{kPa}$ for the very stiff clays. The vertical preconsolidation stress, $\sigma_{\mathrm{c}}^{\prime}$, and over-consolidation ratio, $O C R$, along with the compression $\left(\mathrm{C}_{\mathrm{c}}\right)$ and swelling $\left(\mathrm{C}_{\mathrm{s}}\right)$ indices, were estimated from the oedometer test compression curves, which were corrected for sample disturbance using the Schmertmann method described in Holtz and 
Kovacs (1981). The OCR varied between 14.5 at a depth of $1 \mathrm{~m}$ and 1.1 at a depth of $30 \mathrm{~m}$, as illustrated in Figure 3b while the initial void ratio, $e_{0}$, varied between 1.9 and 0.4 (Figure 3c).

Due to the paucity of consolidated drained triaxial tests on clay samples, their friction angle, $\varphi^{\prime}$ - critical state, $\varphi_{\mathrm{cs}}^{\prime}$, for the soft clay and peak, $\varphi_{\mathrm{p}}^{\prime}$, for the stiff and very stiff clays - were correlated with their plasticity index, PI, as per Equations 1 and 2 respectively (Sorensen and Okkels 2013).

$$
\begin{aligned}
& \varphi_{\mathrm{cs}}^{\prime}=39-11 \log _{10} P I \\
& \varphi_{\mathrm{p}}^{\prime}=44-14 \log _{10} P I
\end{aligned}
$$

The coefficient of earth pressure at rest, $\mathrm{K}_{0}$, for normally and over-consolidated clays was computed using Equation 3 (Jaky 1944) and Equation 4 (Mayne and Kulhawy 1982) respectively.

$$
\begin{gathered}
\mathrm{K}_{0}=1-\sin \varphi_{\mathrm{cs}}^{\prime} \\
K_{0}=\left(1-\sin \varphi_{\mathrm{p}}^{\prime}\right) \mathrm{OCR}^{\sin \varphi_{\mathrm{p}}^{\prime}}
\end{gathered}
$$

The interface friction angle, $\delta$, between the steel pile/hybrid feature and clay was calculated using Equation 5 (Randolph and Wroth 1981).

$$
\delta=\tan ^{-1}\left\{\left(\sin \varphi^{\prime} \times \cos \varphi^{\prime}\right) /\left(1+\sin ^{2} \varphi^{\prime}\right)\right\}
$$

Although soil permeability measurements were available from triaxial tests, their accuracy was questionable as very low values, in the region of $10^{-8} \mathrm{~m} / \mathrm{s}$, were obtained for sand samples. This was thought to be due to the porous stones in the triaxial equipment being clogged by clay particles from previous tests on clay samples. Therefore, the saturated permeability, $k_{\text {sat }}$, of clays was predicted to vary between $7.94 \times 10^{-10}$ and $4.87 \times 10^{-12} \mathrm{~m} / \mathrm{s}$ using Equation 6 (Mbonimpa et al. 2002). 


$$
k_{\mathrm{sat}}=0.01 C_{\mathrm{p}} \frac{\gamma_{\mathrm{w}}}{\mu_{\mathrm{w}}} \frac{e_{0}^{3+x}}{1+e_{0}} \frac{1}{\rho_{\mathrm{s}}^{2} w_{\mathrm{L}}^{2 \chi}}
$$

where

$k_{\text {sat }}$ is in $\mathrm{m} / \mathrm{s}$,

$C_{\mathrm{p}}$ is a constant equal to $5.6 \mathrm{~g}^{2} / \mathrm{m}^{4}$,

$\gamma_{\mathrm{w}}$ is the unit weight of water equal to $9.8 \mathrm{kN} / \mathrm{m}^{3}$,

$\mu_{\mathrm{w}}$ is the dynamic viscosity of water equal to $10^{-3}$ Pa.s,

$\chi$ is a material parameter equal to 1.5 ,

$\rho_{\mathrm{s}}$ is the density of the solid grains in $\mathrm{kg} / \mathrm{m}^{3}$, which is derived from the clay's specific gravity, $G_{S}$, $w_{\mathrm{L}}$ is the liquid limit in $\%$, and

$x$ is parameter that takes into account the effect of tortuosity and is defined as:

$$
x=7.7 \mathrm{w}_{\mathrm{L}}^{-0.15}-3
$$

Based on published literature, the drained Poisson's ratio, $v^{\prime}$, was specified to be 0.25 for soft clays and 0.3 for the stiff and very stiff clays. The stiffness, $E$, of the clays was estimated using the Duncan and Buchignani 1976 correlation with $s_{\mathrm{u}}, O C R$ and $P I$, and ranged between 4.4 and $105 \mathrm{MPa}$ (Figure 3d).

The clay behaviour was represented by the elasto-plastic Modified Drucker-Prager constitutive model, whose yield surface, illustrated in Figure 4, is composed of two segments - a linear pressure dependent shear failure surface, $F_{s}$ (Equation 8 ), and an elliptical cap yield surface, $F_{c}$ (Equation 9). $F_{s}$ is perfectly plastic while $F_{c}$ hardens or softens as a function of the volumetric plastic strain, $\varepsilon_{\mathrm{vol}}^{\mathrm{p}}$. Yielding on $F_{c}$ causes hardening while that on $F_{s}$ causes softening.

$$
\begin{gathered}
F_{s}=t-p_{h} \tan \beta-d=0 \\
F_{c}=\sqrt{\left(p_{h}-p_{a}\right)^{2}+[R t /(1+\alpha-\alpha / \cos \beta)]^{2}}-R\left(d+p_{a} \tan \beta\right)=0
\end{gathered}
$$


where

$t$ is the deviatoric stress, $p_{h}$ is the equivalent hydrostatic pressure, $\beta$ is the angle of friction, $d$ is the material cohesion, $p_{a}$ is a parameter that controls the volumetric plastic strain driven hardening/softening, $R$ is the cap eccentricity (calibrated to be 0.1 ), and $\alpha$ is the radius of the transition surface that provides a smooth intersection between $F_{s}$ and $F_{c}$. For these analyses, the transition surface was omitted; hence $\alpha=0$.

$\beta$ and $d$ were computed by matching them to Mohr-Coulomb triaxial compression (Equations 10 and 11),

$$
\begin{gathered}
\tan \beta=\frac{6 \sin \varphi^{\prime}}{3-\sin \varphi^{\prime}} \\
d=\frac{6 c^{\prime} \cos \varphi^{\prime}}{3-\sin \varphi^{\prime}}
\end{gathered}
$$

and cap hardening was prescribed at $1 \mathrm{~m}$ depth intervals as a piecewise linear function relating the pre-consolidation yield stress, $p_{b}$, and $\varepsilon_{\mathrm{vol}}^{\mathrm{p}}$ (Equation 12).

$$
\varepsilon_{\mathrm{vol}}^{p}=\frac{C_{\mathrm{c}}-C_{\mathrm{s}}}{2.3\left(1+e_{0}\right)} \log _{10} \frac{p^{\prime}}{p_{\mathrm{b}}}
$$

where

$p^{\prime}$ is the mean effective stress.

\subsection{Very dense sand}

The sand had constant $e_{0}$ of 0.503 (Figure 3c), saturated unit weight, $\gamma_{s a t}$, of $20.98 \mathrm{kN} / \mathrm{m}^{3}$ and grain diameter, $d_{10}$, of $0.023 \mathrm{~mm}$. Its $\varphi_{p}^{\prime}$ was determined from consolidated drained triaxial tests to be $33^{\circ}$ whereas its dilatancy angle, $\psi$, was computed to be $5^{\circ}$ (Koerner 1970). Although nonzero values were reported for $c^{\prime}$, it was considered prudent to consider the sand as cohesionless. Its $k_{\text {sat }}$ was computed to be $9.74 \times 10^{-6} \mathrm{~m} / \mathrm{s}$ using Equation 12 (Chapuis 2004).

$$
k_{\mathrm{sat}}=0.024622\left(\frac{d_{10}^{2} e_{0}^{3}}{1+e_{0}}\right)^{0.7823}
$$


where $k_{\text {sat }}$ is in $\mathrm{m} / \mathrm{s}$ and $d_{10}$ is in $\mathrm{mm}$.

The secant modulus corresponding to a stress level of $50 \%$ of the peak strength, $E_{50}^{\prime}$, computed using Equation 13, was considered apt for the sands (Schanz and Vermeer 1998).

$$
E_{50}^{\prime}=E_{\text {ref }} \sqrt{\sigma_{x}^{\prime} / p_{\text {ref }}}
$$

where

$p_{\text {ref }}$ is the atmospheric pressure equal to $100 \mathrm{kPa}$,

$\sigma_{x}^{\prime}$ is the effective lateral stress, and

$E_{\text {ref }}$ is the reference stiffness, specified to be $50 \mathrm{MPa}$ to attain $E_{50}^{\prime}$ values between 63.4 and 80.7 MPa (Figure 3d) that were a close fit to the values reported in results of triaxial tests for a limited number of sand samples.

The Mohr Coulomb model, with a non-associative flow rule, was used to characterise the sand behaviour.

\subsection{Reinforced concrete}

C40/50 reinforced concrete with characteristic cylinder strength of $40 \mathrm{~N} / \mathrm{mm}^{2}$ was simulated using the concrete damaged plasticity model (Lubliner et al. 1989) (Lee and Fenves 1998). It is a continuum elastoplastic model that takes into account damage to quasi-brittle materials under low confining stresses as a result of tensile cracking and compression crushing. At sufficiently high confining stresses, the concrete is assumed to behave as a strain hardening/softening material. The parameters for this class of concrete were obtained from laboratory tests reported by Jankowiak and Lodygowski 2005. The concrete was assigned a density of $2400 \mathrm{~kg} / \mathrm{m}^{3}$, Young's Modulus of $19.7 \mathrm{GPa}$, Poisson's ratio of 0.19 and dilation angle (internal friction angle) of $38^{\circ}$. The reinforcing bars were assumed to be ribbed with density of $7840 \mathrm{~kg} / \mathrm{m}^{3}$, Young's Modulus of $210 \mathrm{GPa}$, Poisson's ratio of 0.3 and characteristic yield strength of $500 \mathrm{MPa}$.

\subsection{Steel}




\section{Loading}

After the soil had achieved geostatic equilibrium, the hybrid monopile system was subjected sequentially to gravity, axial and lateral loads. Pile, fin and skirt installation effects were not taken into account. An axial load, $V$, of 4.3 $\mathrm{MN}$ was applied incrementally to the pile head over duration of $48 \mathrm{~h}$ ( 2 days) to cater for the self-weight of the turbine, tower and transition piece. A lateral load, $H$, of $12.1 \mathrm{MN}$ was applied incrementally at the pile head over duration of $132 \mathrm{~h}(5.5$ days). This duration enabled prescription of a minimum step time increment that was satisfactory in preventing pore pressure oscillation (Vermeer and Verruijt 1981). The resulting overturning moment to lateral load ratio $\left(M_{a} / H\right)$ at mudline was 36 . This correlated to the environmental loading regime monopiles would be subjected to at UK North Sea offshore locations with harsh wind and water depth, $h_{w}$, of $30 \mathrm{~m}$.

Rock armour is commonly provided around a monopile to minimise scouring of the seabed, which has an adverse effect on the dynamic response and lateral capacity of a monopile due to the following:

- The gradual reduction of soil in the scoured region reduces the effective embedment of the monopile and increases the overturning moment on the pile due to an increase in the lever arm of wind and wave loading, and

- A reduction in soil support and stiffness lowers the natural frequency of the structure.

Since clayey soils limit scour development (Whitehouse et al. 2011), it was assumed that the rock armour can be relied upon to contribute to the long-term lateral capacity of hybrid monopiles without undergoing significant attrition. Therefore, its effect on the lateral capacity of hybrid monopiles was assessed by applying a $25 \mathrm{kPa}$ surcharge, over a circular area of 294.5 $\mathrm{m}^{2}$ around the monopile, on top of the footings or on the surface of the fins and the soft clay. 


\section{Model verification}

The FEA model was calibrated using results of a centrifuge test carried out by Lau 2015 to investigate investigate the lateral behaviour of monopiles in Speswhite Kaolin. Carried out at a centrifugal acceleration of $100 \mathrm{~g}$, the model monopile, fabricated of aluminium, in prototype scale, had $D$ of $3.8 \mathrm{~m}, L_{\mathrm{T}}$ of $50 \mathrm{~m}$ and $L$ of $20 \mathrm{~m}$. The clay was submerged to a prototype depth of $4 \mathrm{~m}$, which was limited by the height of the centrifuge strongbox.

With $P I$ of $33 \%, G_{\mathrm{s}}$ of $2.61, \varphi^{\prime}$ of $23.2^{\circ}$ and $O C R$ varying between 15 at mudline and 1.0 at the pile tip, the artificially produced clay was consolidated under $1 g$ conditions prior to the centrifuge test to achieve the required $s_{\mathrm{u}}$ profile, which was measured using a seismic cone penetrometer test. Its $s_{\mathrm{u}}$ increased from $3 \mathrm{kPa}$ at mudline to $33 \mathrm{kPa}$ at the pile tip. A $5 \mathrm{~m}(50 \mathrm{~mm}$ in model scale) layer of dense Hostun sand with relative density of $70 \%$ was provided beneath the Speswhite Kaolin to accelerate the consolidation process.

The model monopile was installed to a prototype depth of $16 \mathrm{~m}$ at $1 \mathrm{~g}$ with the remaining $4 \mathrm{~m}$ installed at $100 \mathrm{~g}$ following 4 hours of in-flight consolidation. This was considered sufficient in mobilising the shaft friction and end bearing capacity of the pile. After the application of an axial load, $V$, of $4 \mathrm{MN}$, the pile head was displaced laterally, at a rate of $0.05 \mathrm{~mm} / \mathrm{s}$, to a maximum displacement, $y_{\mathrm{a}}$, of $6 \mathrm{~m}$ (under prototype scale). As illustrated in Figure 5, a very good agreement was obtained between the results of the FEA model and centrifuge test (CT). Similar comparisons were made with more extensive centrifuge tests with different clay properties as reported by Haiderali et al. 2014.

\section{Results}

\subsection{Lateral capacity}

The deformation of an offshore wind turbine tower can adversely affect its nacelle by disrupting the distribution of lubrication in gearboxes, imposing additional loads on bearings and creating 
abnormal component forces. Therefore, the performance of these hybrid monopiles is evaluated in terms of serviceability rather than ultimate failure.

The efficacy of the hybrid features in limiting pile displacement was assessed by comparing the ratio of the lateral load required by the hybrid monopile, $H_{\text {Hybrid, }}$ and that by the monopile-only,

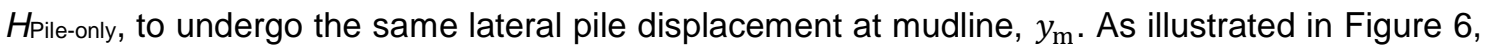
without taking into account the surcharge load, $H_{\text {Hybrid }}$ was on average 1.08 to 2.27 times greater than $H_{\text {Pile-only. }}$ Inclusion of the surcharge load increased the $H_{\text {Hybrid }} / H_{\text {Pile-only }}$ ratio to between 1.14 and 2.44. In this regard, the most effective was the skirted steel footing (2.27-2.44) followed by the finned pile (1.6-1.66) and the RC footing (1.19-1.32) whereas the least effective was the non-skirted steel footing (1.08-1.14).

A comparison based on pile displacements can slightly over-estimate the effect of these hybrid features mainly because the increased flexural rigidity they provide to the monopile results in its point of rotation to move up leading to an increase in the pile head rotation at mudline, $\theta_{m}$, which has to be limited to $0.25^{\circ}$ during the design life of a monopile (Malhotra 2011). Therefore, a better performance indicator is the serviceability lateral pile capacity, $H_{\mathrm{serv}}$, at which $\theta_{\mathrm{m}}$ is equal to $0.25^{\circ}$. For the monopile-only, $H_{\text {serv }}$ was determined to be $6.35 \mathrm{MN}$. When combined with the non-skirted RC and steel footings, $H_{\text {serv }}$ increased by a factor of 1.10 and 1.04 , to 7.0 and 6.6 MN respectively. On the other hand, when used with the skirted steel footing and fins, $H_{\text {serv }}$ increased by considerably larger multipliers of 1.72 and 1.30 , to 10.95 and $8.25 \mathrm{MN}$. This represented an increase of $4-72 \%$ over the 4 hybrid options, with the skirted and non-skirted steel footings being the most and least effective respectively.

As illustrated in Figure 7, when the hybrid features were used in combination with the rock armour, $H_{\text {serv }}$ was enhanced by a further $4 \%$ for the non-skirted steel footing, $5 \%$ for the finned monopile and $9 \%$ for the non-skirted RC and skirted steel footings to yield $H_{\text {serv }}$ of $7.55,6.85$, 11.5 and $8.55 \mathrm{MN}$ respectively. This denoted an overall increase in $H_{\mathrm{serv}}$ of $8-81 \%$.

The improvement in lateral capacity brought about by these 8 hybrid options is summarised in Table 2. 
Table 2 Lateral pile capacity at serviceability, $H_{\text {serv }}$

\begin{tabular}{lllll}
\hline \multirow{2}{*}{ Hybrid feature } & $H_{\text {serv }}(\mathrm{MN})$ & & \multicolumn{2}{c}{ \% Increase in $H_{\text {serv }}$} \\
& No surcharge & With surcharge & No surcharge & With surcharge \\
\hline Monopile-only & 6.35 & - & - & - \\
RC footing & 7.00 & 7.55 & 10 & 19 \\
$\begin{array}{l}\text { Non-skirted } \\
\text { steel footing }\end{array}$ & 6.60 & 6.85 & 4 & 8 \\
$\begin{array}{l}\text { Skirted steel } \\
\text { footing }\end{array}$ & 10.95 & 11.5 & 72 & 81 \\
Fins & 8.25 & 8.55 & 30 & 35 \\
\hline
\end{tabular}

The $30-35 \%$ increase in lateral capacity brought about by the fins was less than the $40-76 \%$ improvement in sand reported by Bienen et al. 2012 and Peng et al. 2010. On the other hand, the provision of a skirt to the steel footing increased the pile lateral capacity in clay by a greater proportion (68-73\%) in comparison to the 50\% increase in sand reported by Arshi et al. 2013. However, this is to be regarded as an indirect comparison as skirt lengths were not stated by Arshi et al. 2013. Finally, contrary to the findings of Lehane et al. 2010, both the skirted and non-skirted steel footings enhanced the monopile lateral capacity in clay. However, owing to the relatively small improvement brought about by the non-skirted steel footing, increased material and installation costs would not justify its implementation.

\subsection{Shear force and bending moment}

A better understanding of the mechanisms through which these hybrid features enhanced the monopile lateral capacity was obtained by examining the shear force, $F$, and bending moment, $M$, developed along the embedded depth of the hybrid monopile. To ensure the results were generally applicable, independent of specific loading conditions, the shear force and bending moment have been normalised by the applied lateral load, $H$, and the overturning moment at mudline, $M_{a}$, respectively.

The pile shear force profile, shown in Figure 8 for the hybrid monopiles with surcharge at $H$ of 5.5 MN, indicates that with the exception of the fins, the rest of the hybrid features provide a relatively large restoring force. The magnitude of the restoring force varied between $0.25 \mathrm{H}$ for 
The effectiveness of the non-skirted steel footing diminished very quickly with pile depth such that the peak shear force in the hybrid monopile was $89 \%$ of that in the pile-only. The RC footing retained its influence with depth slightly better such that its peak shear force was $82 \%$ of that in the pile-only. The positive influence of the skirt on the steel footing is clearly evident with the shear force significantly reduced in the lower half of the pile and the peak shear force, which was $92 \%$ of that in the pile-only, occurring at a relatively shallow depth. Although the fins did not generate a restoring force, they were effective in lowering the peak shear force in the finned pile by $8 \%$ relative to the pile-only.

Similarly, the bending moment profile, illustrated in Figure 9 for the hybrid monopiles with surcharge at $H$ of $5.5 \mathrm{MN}$, demonstrates that all the hybrid features except the fins generate a resisting moment. The magnitude of the resisting moment varied between $0.038 M_{a}$ for the skirted steel footing, $0.043 M_{a}$ for the RC footing and $0.054 M_{a}$ for the non-skirted steel footing, with surcharge included, and $0.023,0.041$ and $0.047 M_{a}$ without surcharge respectively. Consequently, relative to the pile-only, bending moments were lower throughout the embedded length of the hybrid monopiles. Utilising surcharge, the skirted steel footing was best performing with the peak bending moment in the pile below the skirt being $58 \%$ of that in pile-only. Even though the non-skirted $\mathrm{RC}$ and steel footings contributed a larger resistive moment relative to the skirted steel footing, they led to respective reductions of only $12 \%$ and $11 \%$ in the peak bending moment thus explaining their inefficiency in improving the pile lateral capacity. As a result of the fins generating a negligible resisting moment, the reduction in the finned pile's peak bending moment was a paltry $2 \%$. 


\section{Discussion}

On the basis of these results, the skirted steel footing, with and without surcharge, was the most effective hybrid option for enhancing the monopile lateral capacity. Its superiority is attributed to the extra soil resistance generated against the skirt, which can be visualised in Figure 10 by higher lateral soil stresses in its vicinity. As shown by Figure 11a, in comparison to the pile-only, the soil resistance along the skirt length was significantly greater, especially in the stiff clay layer where it was on average $716 \%$ higher at maximum lateral load. Beyond the skirt tip, there was a sharp drop in soil resistance, which suggests that most of the lateral load was being resisted by the clay adjacent to the skirt. This translated to a considerable reduction in the lateral displacement of the hybrid pile relative to the pile-only (Figure 11b). It can also be inferred from the reduction in soil resistance at the pile toe that part of this hybrid pile was redundant and that its embedded length could be reduced. However, this needs further investigation.

Even though the fins did not provide significant flexural stiffness to the pile, they were the next best option due to additional soil resistance being invoked against them. Figure 12a shows that, at maximum lateral load, the soil resistance against the finned section was on average $64 \%$ greater relative to the pile-only. At a depth, $z$, of $12.5 \mathrm{~m}(z / L$ of 0.417$)$, just prior to the termination of the fins, there was a marked reduction in soil resistance, the effect of which cascaded to the underlying soil until the pile toe. As illustrated in Figure 12b, the increased soil resistance along the finned section led to a reduction in the lateral displacement throughout the finned pile relative to the pile-only. Interestingly, a slightly greater deflection of the fin toe, or 'toe-kick', occurred due to increased shearing there. This was also manifested by a 'kink' in the shear force profile immediately after the termination of the fins, at $z / L$ of 0.517 (Figure 8). Increased shear stresses in the soil adjacent to the fins that are perpendicular to the direction of lateral loading can be visualised in Figure 13.

Of the 4 fins provided, the 2 perpendicular to the direction of lateral loading were considered most susceptible to plastic yielding. The presence of both sagging and hogging bending moments along the length of the perpendicular fins, shown in Figure 14a, indicates that the fins undergo twisting when laterally loaded. The deformed shape of the perpendicular fin, illustrated 
in Figure 14b, confirms this. Figure 14a also shows that fin sections between the depth of 2.5 and $4 \mathrm{~m}(z / L$ ratio of 0.083 to 0.133$)$ experience the most bending. However, up to the maximum lateral load of $12.1 \mathrm{MN}$, these fin sections had not undergone plastic deformation as the bending moment did not even exceed the elastic yield moment, $M_{\mathrm{y}}$, of $0.402 \mathrm{MNm}$, let alone the plastic moment, $M_{\mathrm{p}}$, of $0.603 \mathrm{MNm}$ (Figure 15).

It can therefore be postulated that the relative inefficiency of the non-skirted $R C$ and steel footings can be attributed to their reliance on the resistance afforded by the soft clay beneath the footings. Finally, the dead load from the rock armour interacted positively with the hybrid monopiles and enhanced the lateral pile capacity by a further $4-9 \%$.

\section{Conclusion}

3D soil-pore fluid coupled FEA was undertaken to assess the effect of hybrid features, namely non-skirted RC footing, non-skirted steel footing, skirted steel footing and steel fins, on the lateral response of a $5 \mathrm{~m}$ diameter monopile in clay. The beneficial influence of rock armour, represented by a surcharge load on the hybrid features, was incorporated into all the analyses.

Results indicated a positive interaction between the hybrid features, the rock armour and the monopile leading to an increase in its lateral capacity at serviceability. The skirted steel footing, followed by the steel fins, were found to be the most effective hybrid options. However, experimental research should be undertaken to verify the effectiveness of these hybrid features.

\section{Acknowledgements}

The authors would like to acknowledge DONG Energy for providing the factual offshore wind farm site investigation report used for developing the soil model. 


\section{References}

Arshi HS, Stone KJL, Vaziri M et al. (2013). Modelling of monopile-footing foundation system for offshore structures in cohesionless soils. In Proceedings of the 18th International Conference on Soil Mechanics and Geotechnical Engineering, pp. 2307-2310.

Bienen B, Dührkop F, Grabe J, Randolph MF and White DJ (2012) Response of piles with wings to monotonic and cyclic lateral loading in sand. J Geotech Geoenviron 138(3): 364375.

BSI (2004) BS EN 1992 Eurocode 2: Design of concrete structures. Design Manual. British Standards Institution, London, UK.

Chapuis RP (2004) Predicting the saturated hydraulic conductivity of sand and gravel using effective diameter and void ratio. Can Geotech J 41(5): 787-795.

Dassault Systèmes (2012) Abaqus/Standard Version 6.12-2. Computer Program. Dassault Systèmes Simulia Corp, Providence, USA.

Danish Standards (1998) DS 415: Danish code of practice for foundation engineering, $4^{\text {th }}$ ed. Danish Standards, Nordhavn, Denmark.

Duncan JM and Buchignani AL (1976) An engineering manual for settlement studies. Technical Report. Berkeley, USA.

EWEA (The European Wind Energy Association) (2013) Deep water: The next step for offshore wind energy. Technical Report. EWEA, Brussels, Belgium.

Gorst NJS, Williamson SJ, Pallett PF and Clark LA (2003). Friction in temporary works. Technical Report. Birmingham, pp. 1-53.

Haiderali AE (2015) Numerical modelling of monopiles for offshore wind farms. PhD Dissertation, University of Cambridge, UK.

Haiderali AE, Lau BH, Haigh SK and Madabhushi SPG (2014) Lateral response of monopiles using centrifuge testing and finite element analysis. In Physical Modelling in Geotechnics (Gaudin and White (eds)). Taylor and Francis Group, London, UK, pp. 743-749.

Holtz RD and Kovacs WD (1981) An introduction to geotechnical engineering. Prentice-Hall, Englewood Cliffs, New Jersey, USA, pp. 328-335.

Houlsby GT, Ibsen LB and Byrne BW (2005) Suction caissons for wind turbines. In Frontiers in Offshore Geotechnics (Gourvenec and Cassidy (eds)). Taylor \& Francis Group, London, UK, pp. 75-93.

Jaky J (1944) The coefficient of earth pressure at rest. In Hungarian (A nyugalmi nyomas tenyezoje). Journal of the Society of Hungarian Architects and Engineers 78(22): 355-358.

Jankowiak T and Lodygowski T (2005) Identification of parameters of concrete damage plasticity constitutive model. Foundations of Civil and Environmental Engineering 6: 53-69.

Koerner RM (1970) Effect of particle characteristics on soil strength. J Soil Mech Found DivASCE 96 (SM4): 1221-1234.

Lau BH (2015) Cyclic behaviour of monopile foundations for offshore wind turbines in clay. PhD Dissertation, University of Cambridge, UK. 
Lee $\mathrm{J}$ and Fenves GL (1998). Plastic-damage model for cyclic loading of concrete structures. J. Eng. Mech 24(8): 892-900.

Lehane BM, Powrie W and Doherty JP (2010) Centrifuge model tests on piled footings in clay for offshore wind turbines. In Frontiers in Offshore Geotechnics II (Gourvenec and White (eds)). Taylor and Francis Group, London, UK, pp. 605-610.

Lehane BM, Pedram B, Doherty JA and Powrie W (2014) Improved performance of monopiles when combined with footings for tower foundations in sand. $J$ Geotech Geoenviron 140(7): 04014027.

LORC (Lindoe Offshore Renewables Center) (2011) List of Offshore Wind Farms. See http://www.lorc.dk/offshore-wind-farms-map/list (accessed 14/02/2015).

Lubliner J, Oliver J, Oller S and Oñate E (1989). A Plastic-damage model for concrete. Int. J. Solids Struct., 25(3): 229-329.

Malhotra S (2011) Design and construction considerations for offshore foundations in North America. In Wind Turbines (Al-Bahadly I (ed)). InTech, Rijeka, Croatia, pp 231-264.

Mayne PW and Kulhawy FH (1982) KO-OCR relationships in soil. J Geotech Eng-ASCE 108(GT6): 851-872.

Mbonimpa M, Aubertin M, Chapuis RP and Bussière B (2002) Practical pedotransfer functions for estimating the saturated hydraulic conductivity. Geotechnical and Geological Engineering 20(3): 235-259.

Nasr AMA (2014) Experimental and theoretical studies of laterally loaded finned piles in sand. Can Geotech J 51: 381-393.

Peng J-R, Rouainia M and Clarke BG (2010) Finite element analysis of laterally loaded fin piles. Computers and Structures 88: 1239-1247.

Randolph, MF and Wroth CP (1981). Application of the failure state in undrained simple shear to the shaft capacity of driven piles. Géotechnique 31(1): 143-157.

Schanz T and Vermeer PA (1998) On the stiffness of sands. Pre-failure Deform. Behav. Geomaterials, (Jardine, Davies, Hight, Smith et al. (eds)). Thomas Telford Limited, London, UK, pp. 383-387.

Sorensen KK and Okkels N (2013) Correlation between drained shear strength and plasticity index of undisturbed overconsolidated clays. In Proceedings of the 18th International Conference on Soil Mechanics and Geotechnical Engineering, pp. 423-428.

Stone KJL, Newson TA, El Marassi M et al. (2011) An investigation of the use of a bearing plate to enhance the lateral capacity of monopile foundations. In Frontiers in Offshore Geotechnics II (Gourvenec and White (eds)). Taylor and Francis Group, London, UK, pp. 623-628.

Van Oord ACZ (2003). Scour protection for 6MW OWEC with monopile foundation in North Sea. Technical Report. Gorinchem, The Netherlands, pp. 1-21.

Vermeer PA and Verruijt A (1981) An accuracy condition for consolidation by finite elements. Int $J$ Numer Anal Met 5:1-14.

Whitehouse RJS, Harris JM, Sutherland J and Rees J (2011) The nature of scour development and scour protection at offshore windfarm foundations. Mar Pollut Bull 62(1):73-88. 
Figure 1. Geometry of hybrid features, (a) RC footing, (b) Steel footing, (c) Skirted steel footing, (d) Steel fins

Figure 2. Monopile-RC footing-soil model and mesh. Inset shows close-up of the monopileskirted steel footing-soil model

Figure 3. Variation in geotechnical parameters with depth, (a) undrained shear strength (b)

Over-consolidation ratio, (c) initial void ratio, (d) stiffness

Figure 4. Modified Drucker-Prager yield surface

Figure 5. Verification of FEA model using centrifuge test (CT), (a) lateral load-displacement curve, (b) bending moment profile at applied pile head displacement, $y_{\mathrm{a}}$, of $1.61 \mathrm{~m}\left(\mathrm{y}_{\mathrm{m}}=0.5 \mathrm{~m}\right)$, (c) lateral pile displacement profile at $y_{\mathrm{a}}=1.61 \mathrm{~m}\left(y_{\mathrm{m}}=0.5 \mathrm{~m}\right)$

Figure 6. Relative magnitude of lateral load required to cause hybrid monopile displacement at mudline equivalent to the monopile-only

Figure 7. Relationship between the lateral load and the pile rotation at mudline for the hybrid options with rock armour

Figure 8. Shear force profiles at a lateral load of $5.5 \mathrm{MN}$

Figure 9. Bending moment profiles at a lateral load of $5.5 \mathrm{MN}$

Figure 10. Higher lateral soil stresses against the skirt (deformation scale factor of 5; stress in $\mathrm{kPa})$

Figure 11. Comparison of results at maximum lateral load for pile-only and hybrid pile with skirted footing and surcharge (a) soil resistance profile (b) lateral pile displacement profile Figure 12. Comparison of results at maximum lateral load for pile-only and finned pile with surcharge (a) soil resistance profile (b) pile lateral displacement profile

Figure 13. Increased shear stresses in the soil adjacent to the perpendicular fins (shear stress at the base of the pile omitted for clarity) (deformation scale factor of 1 ; stress in $\mathrm{kPa}$ )

Figure 14. Perpendicular fin (a) bending moment profile at maximum lateral load (b) deformed shape (exaggerated using a deformation scale factor of 15)

Figure 15. Evolution of bending moment with lateral load in the perpendicular fin 

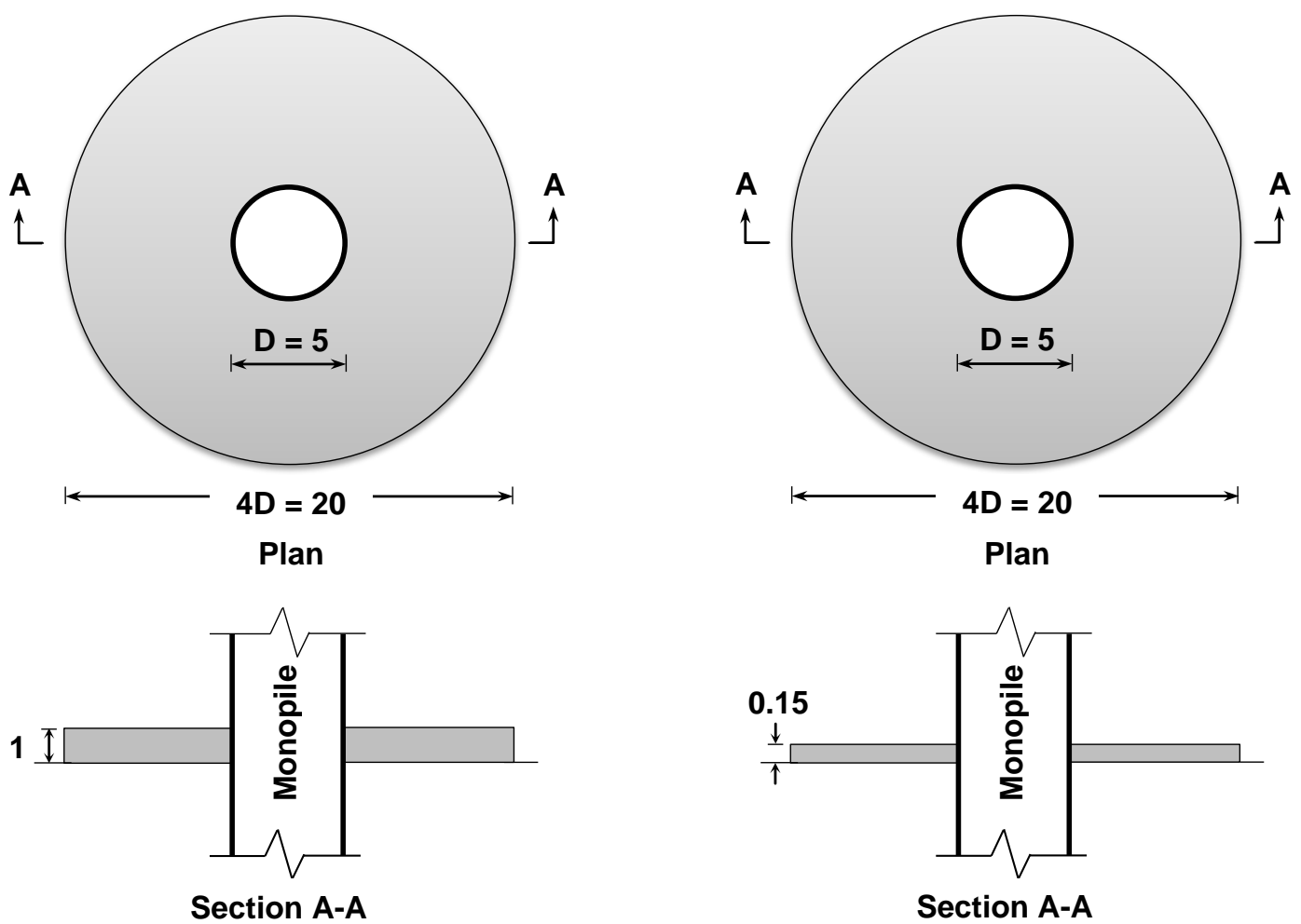

(a)

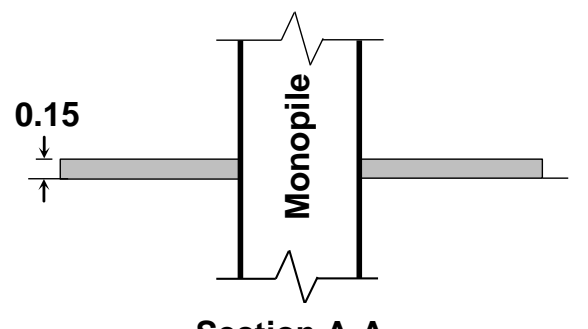

Section A-A

(b)
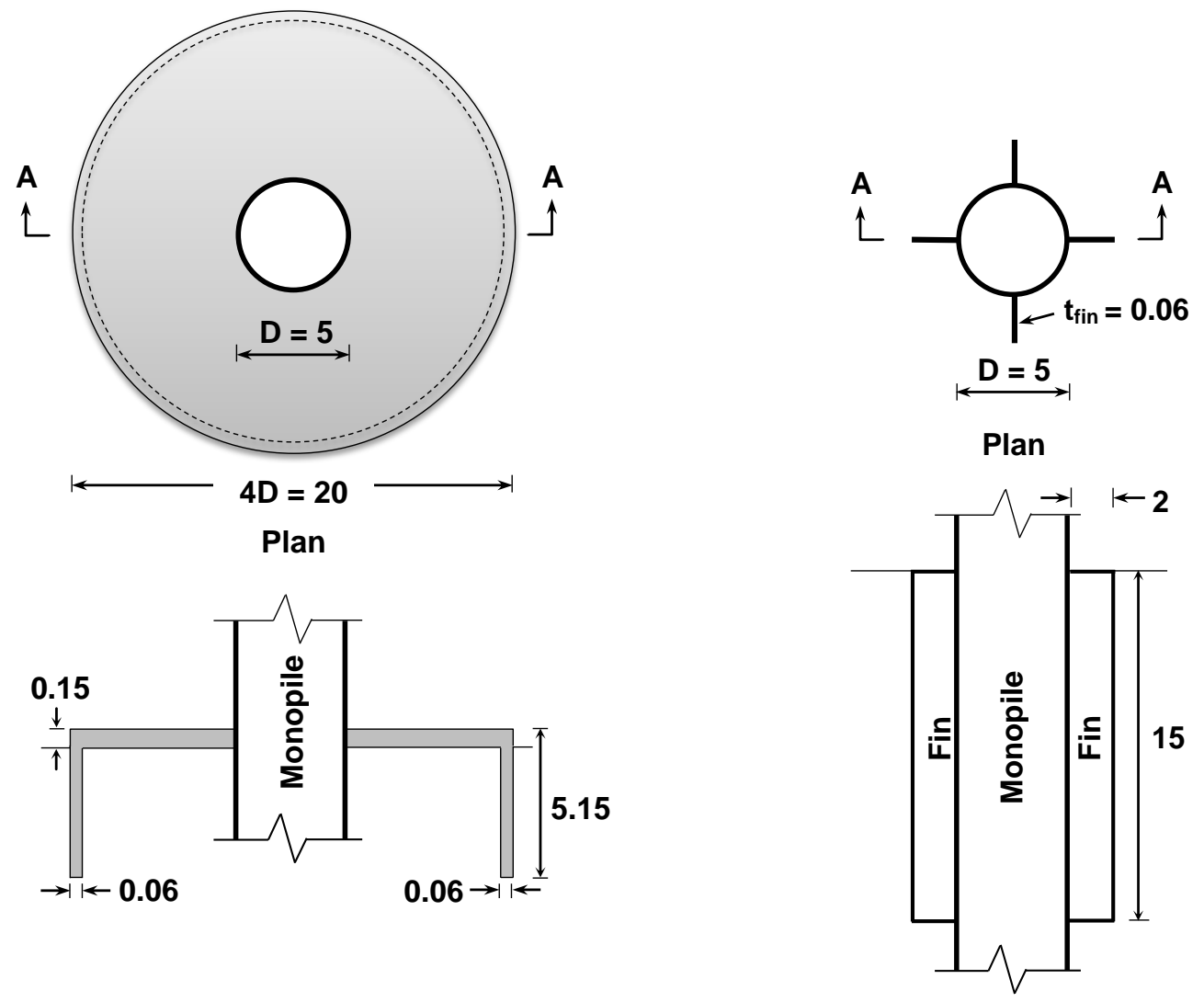

Section A-A

(c)
Not to scale

All dimensions in $\mathrm{m}$
Section A-A

(d) 


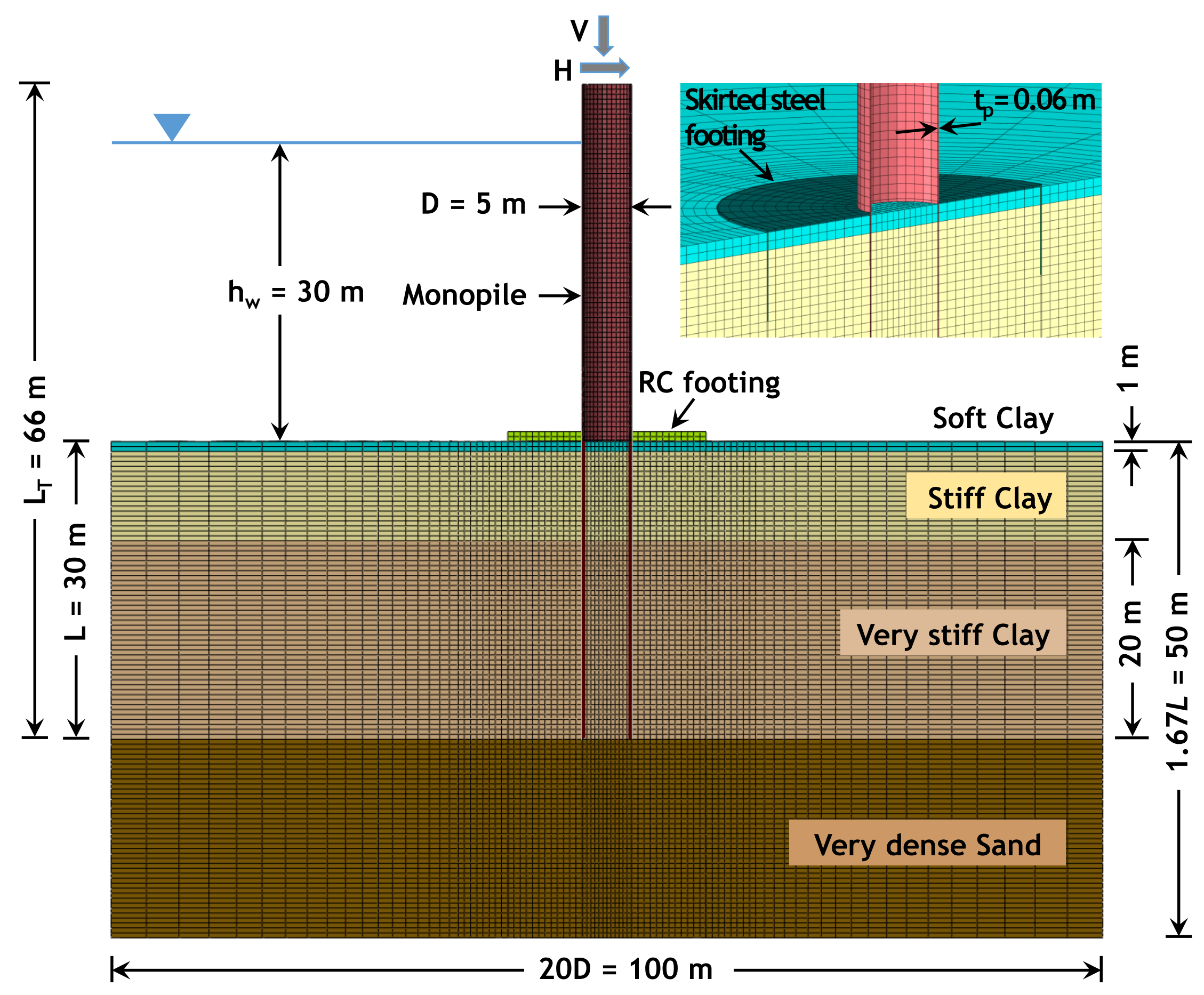




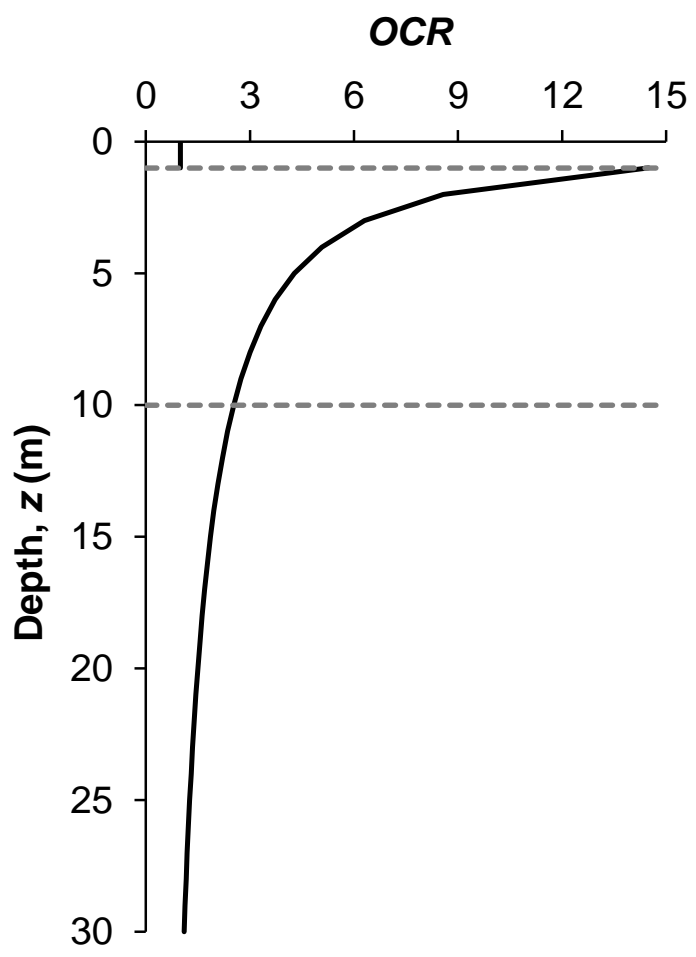

(a)

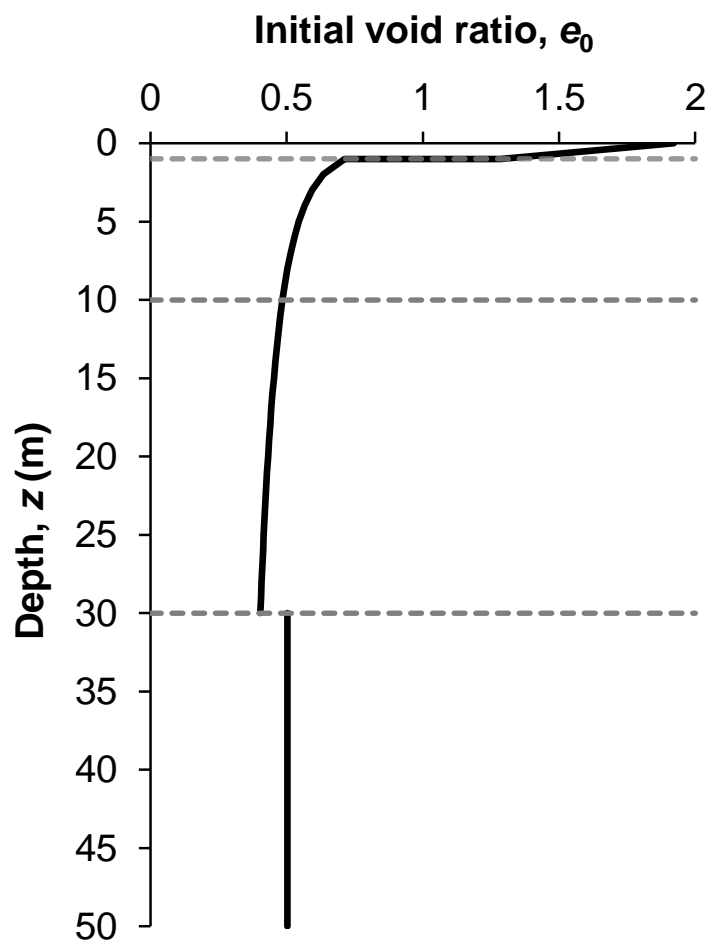

(c)

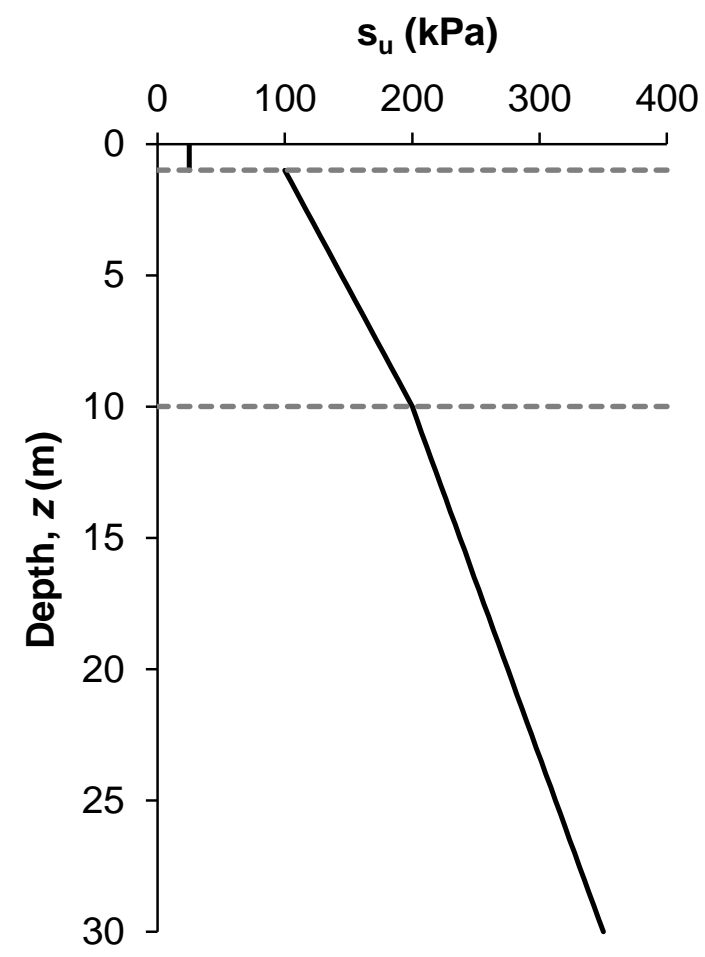

(b)

Soil stiffness, $E(\mathrm{MPa})$

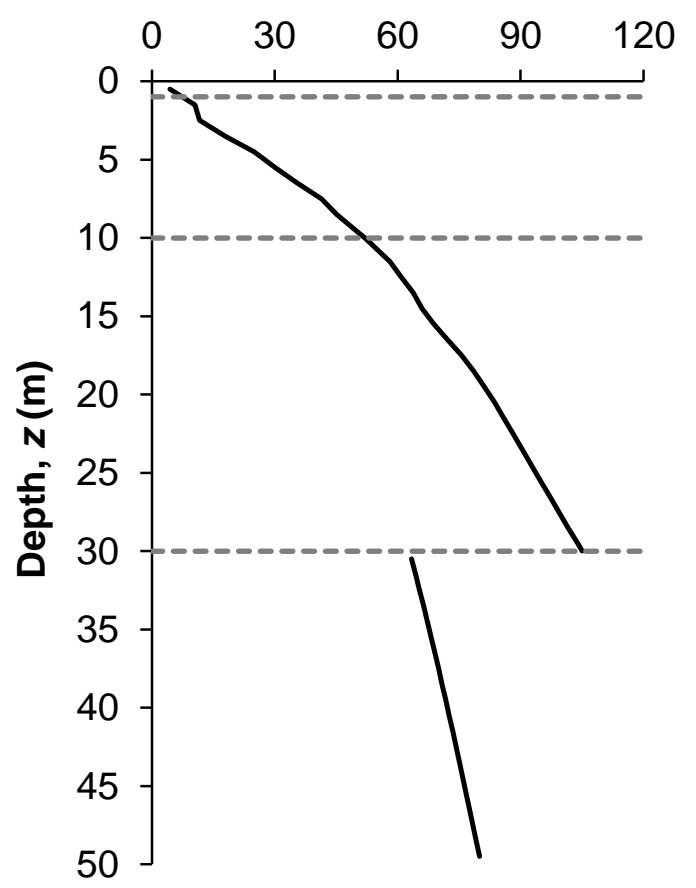

(d) 


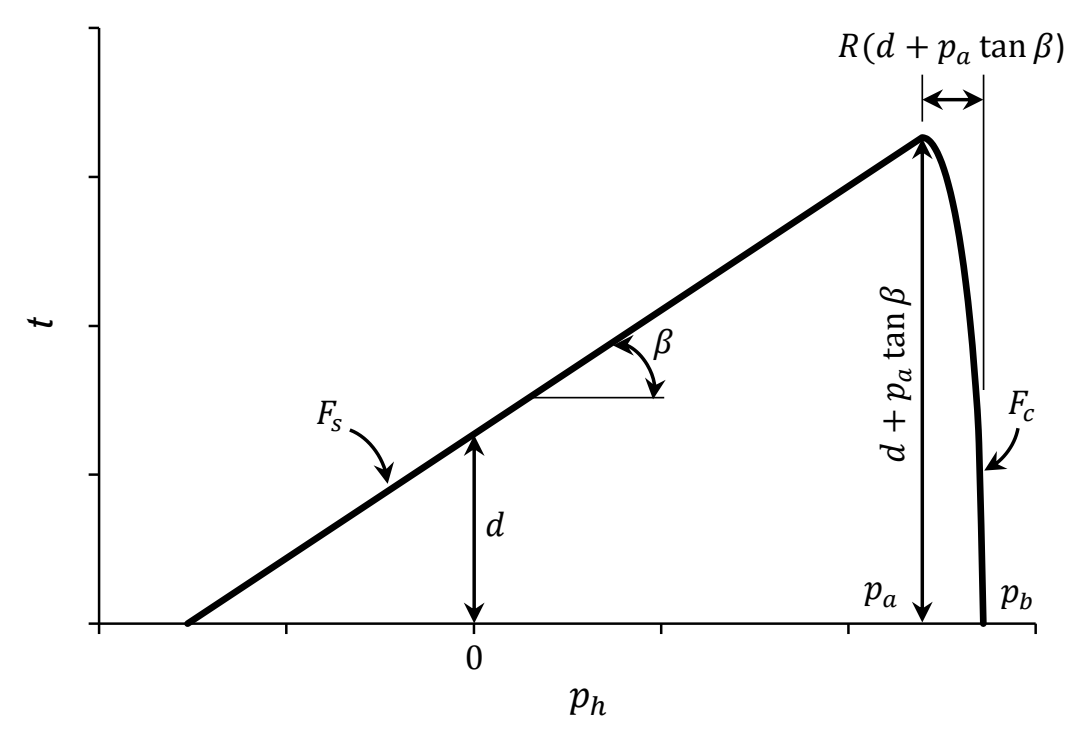

Figure 4 
Figure $5 b$

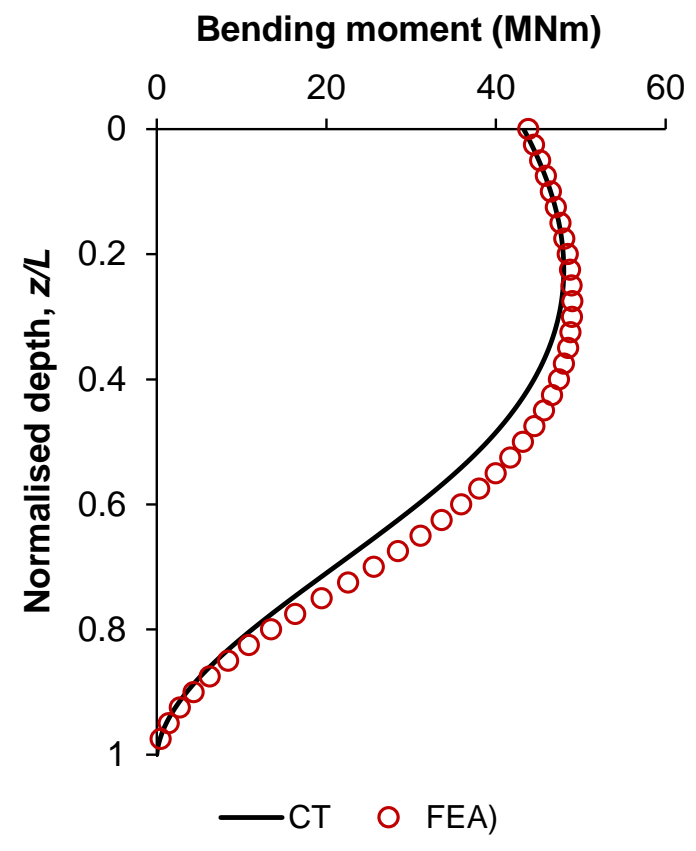


Figure 6

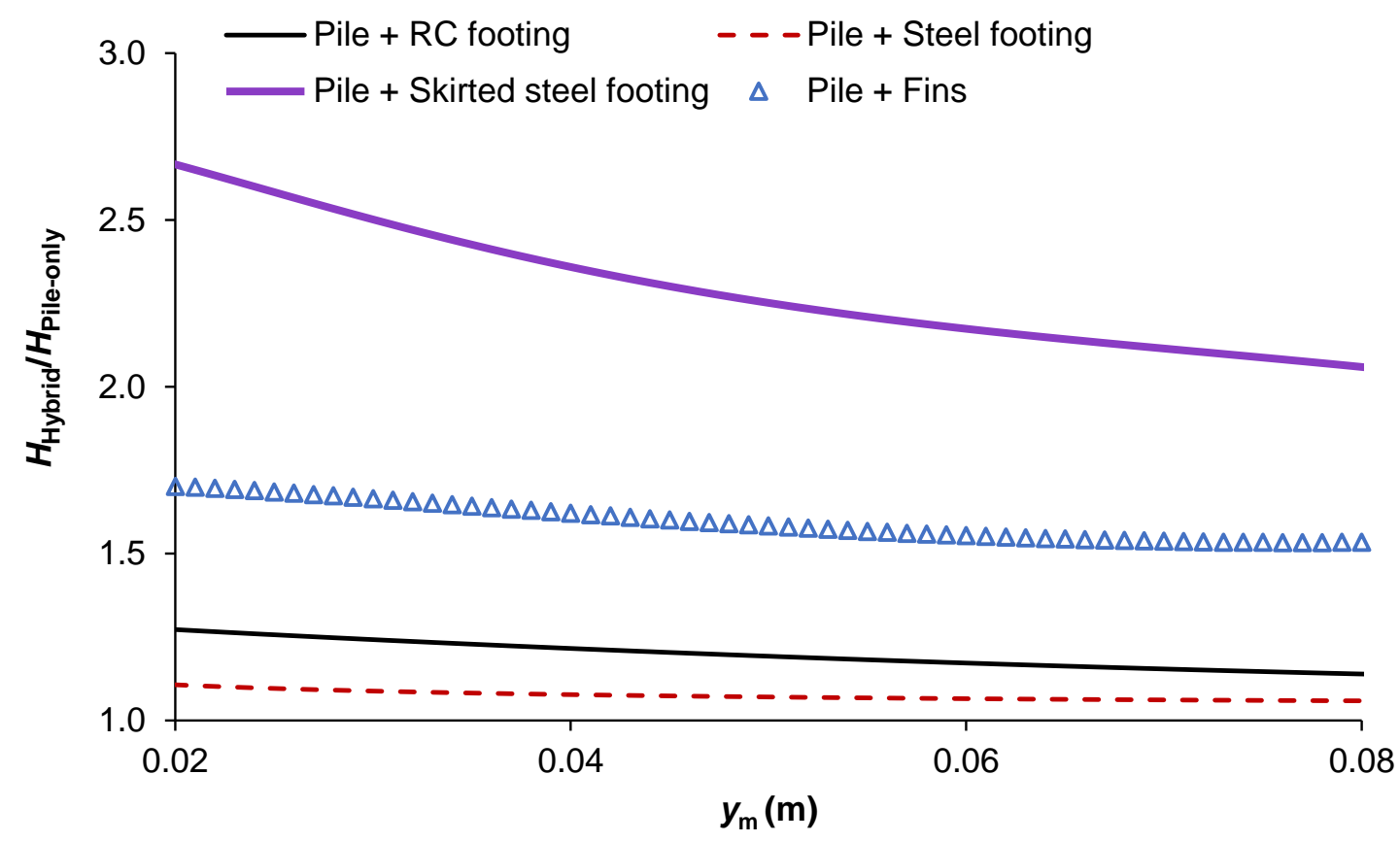




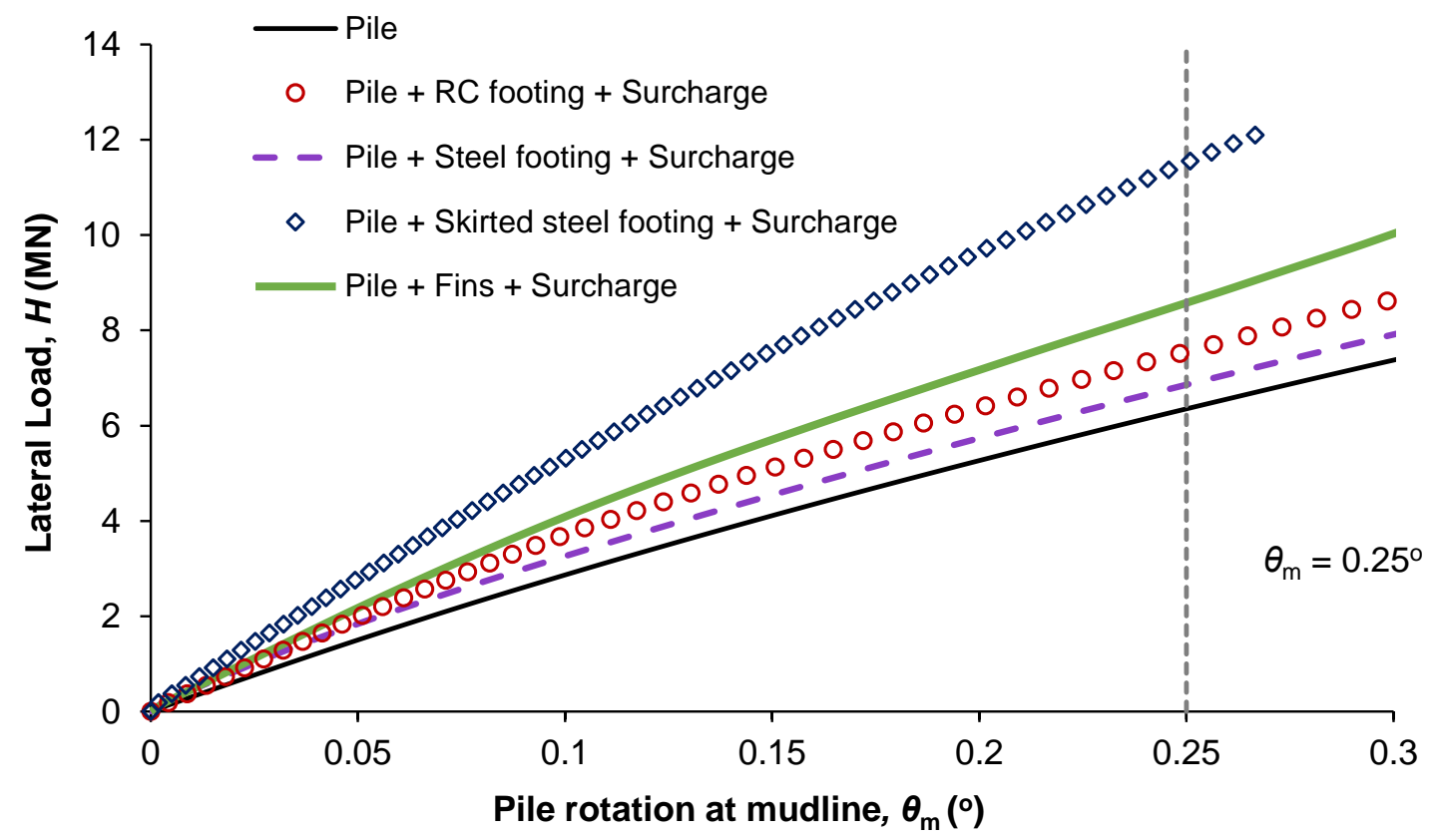




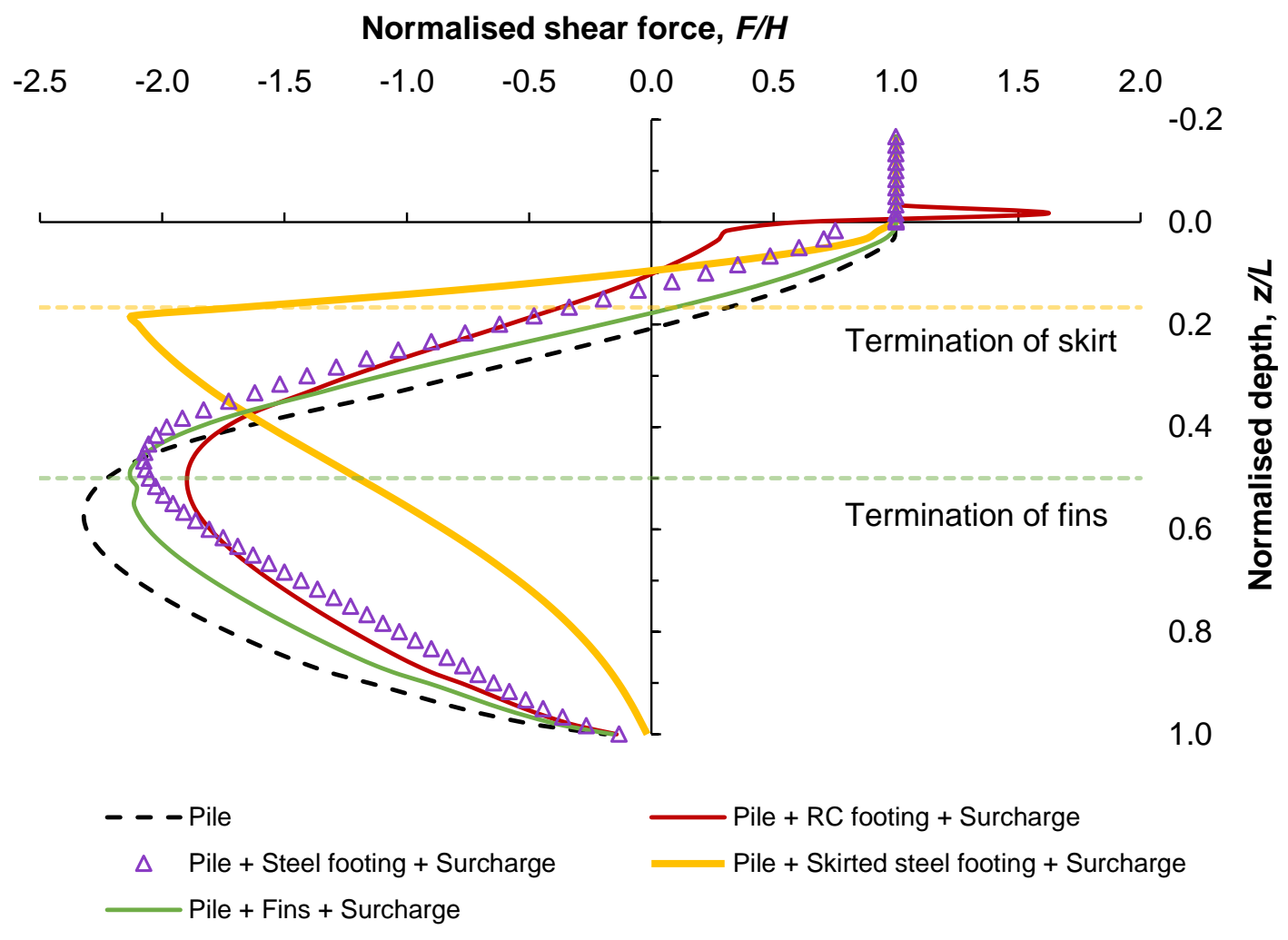




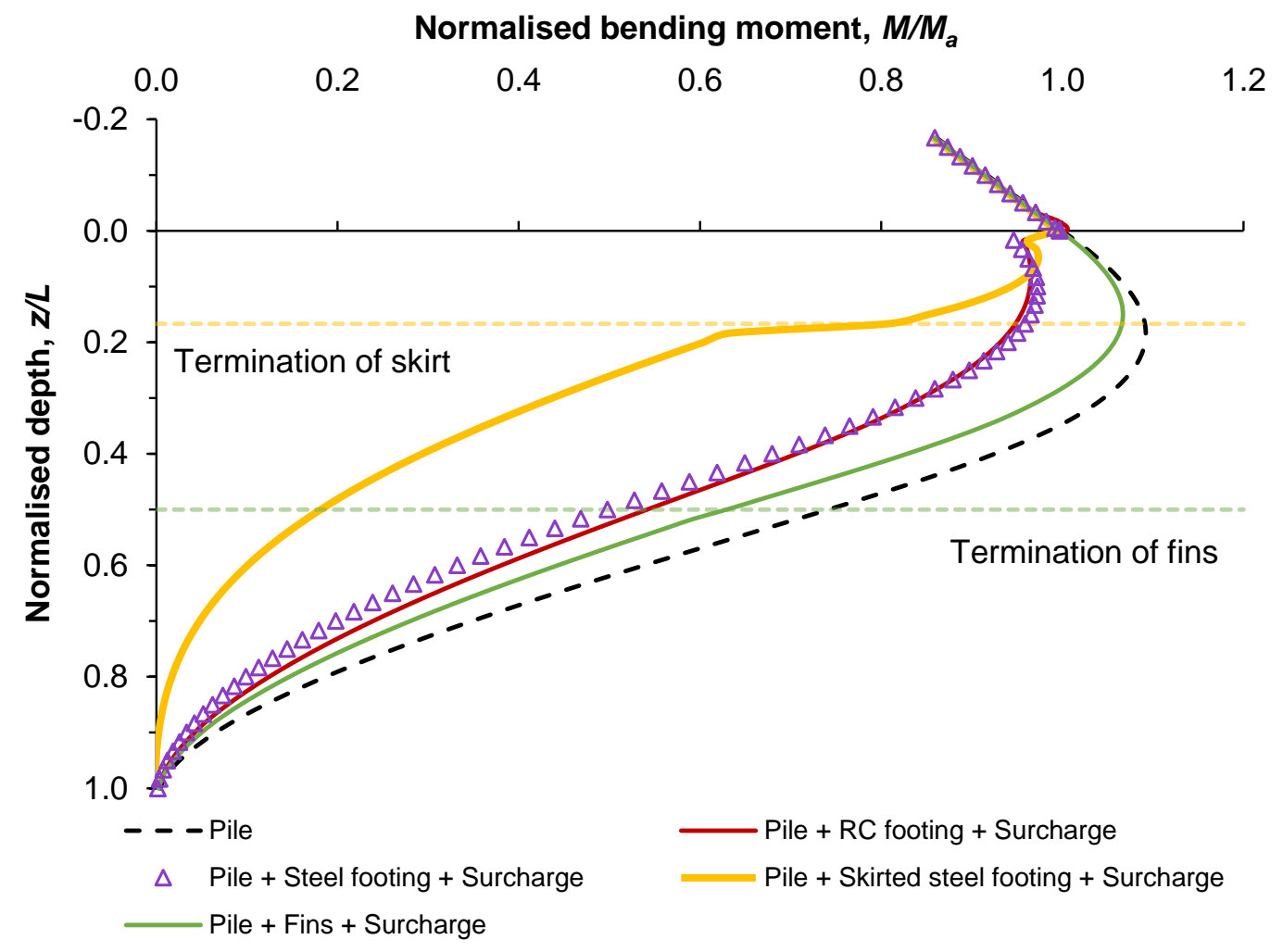


S, S11

(Avg: 75\%)
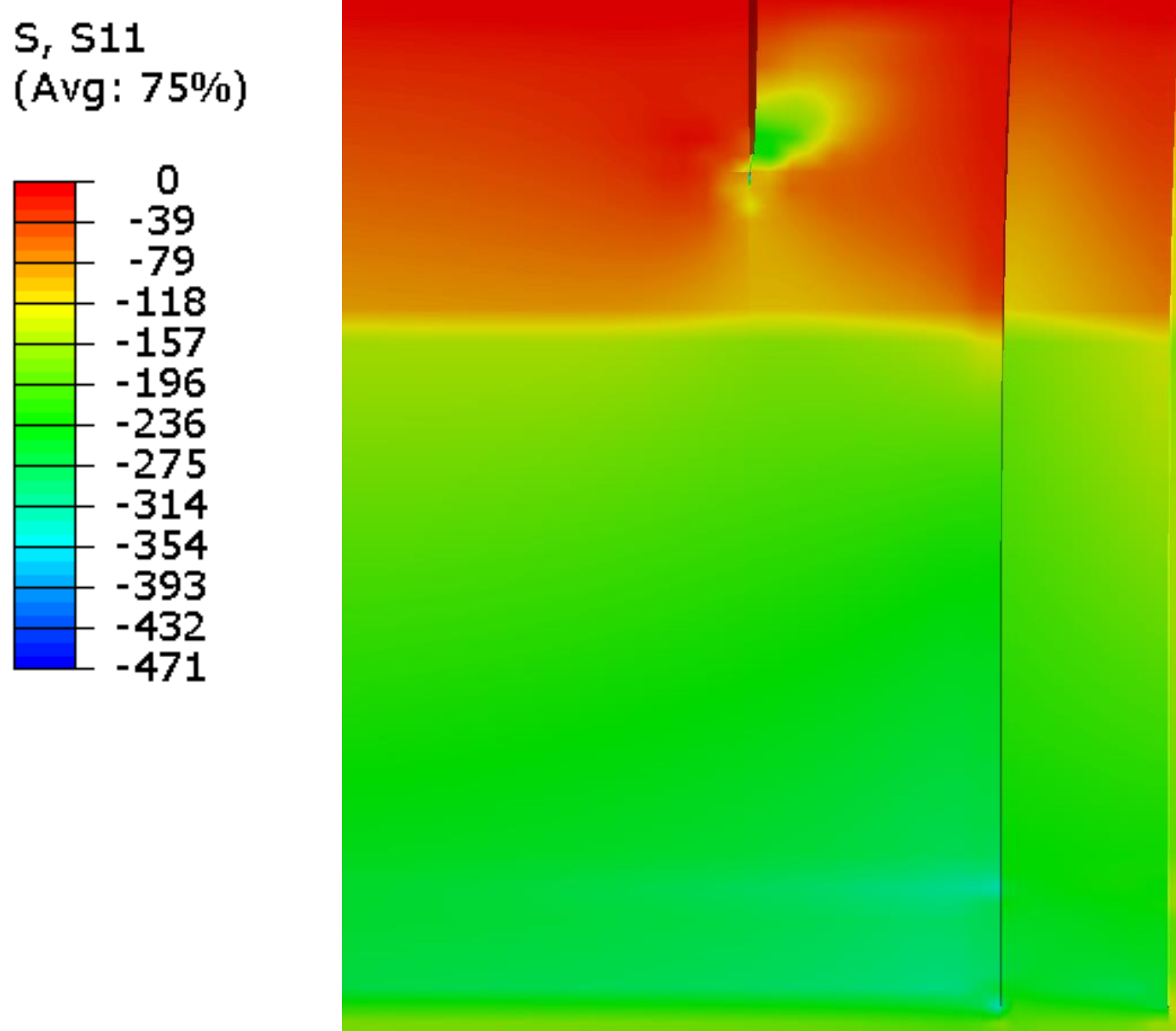


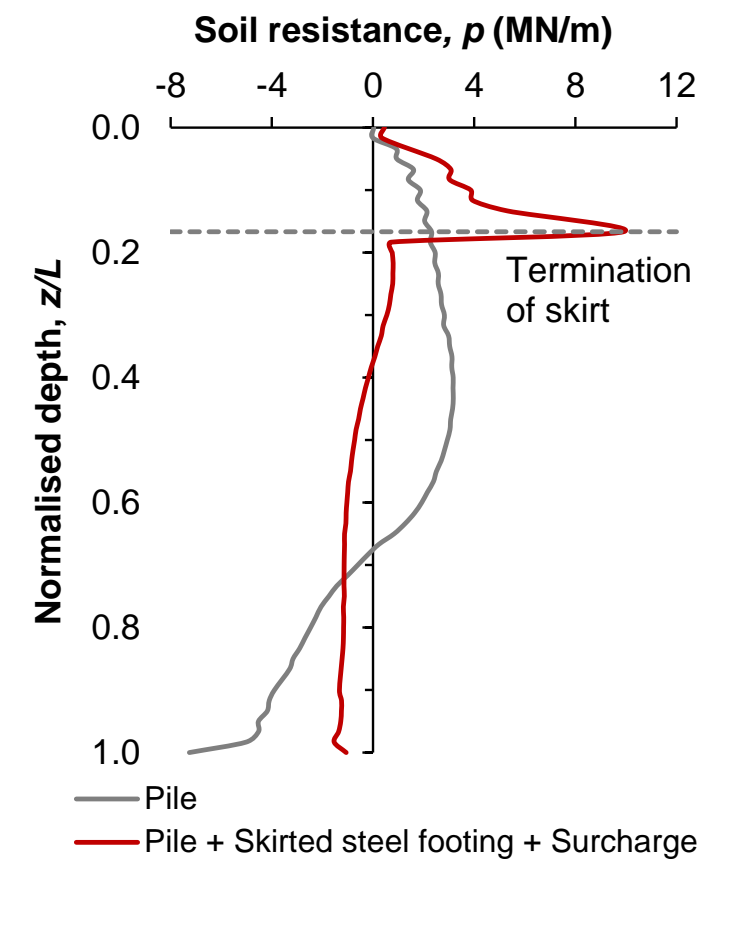

Figure 11a

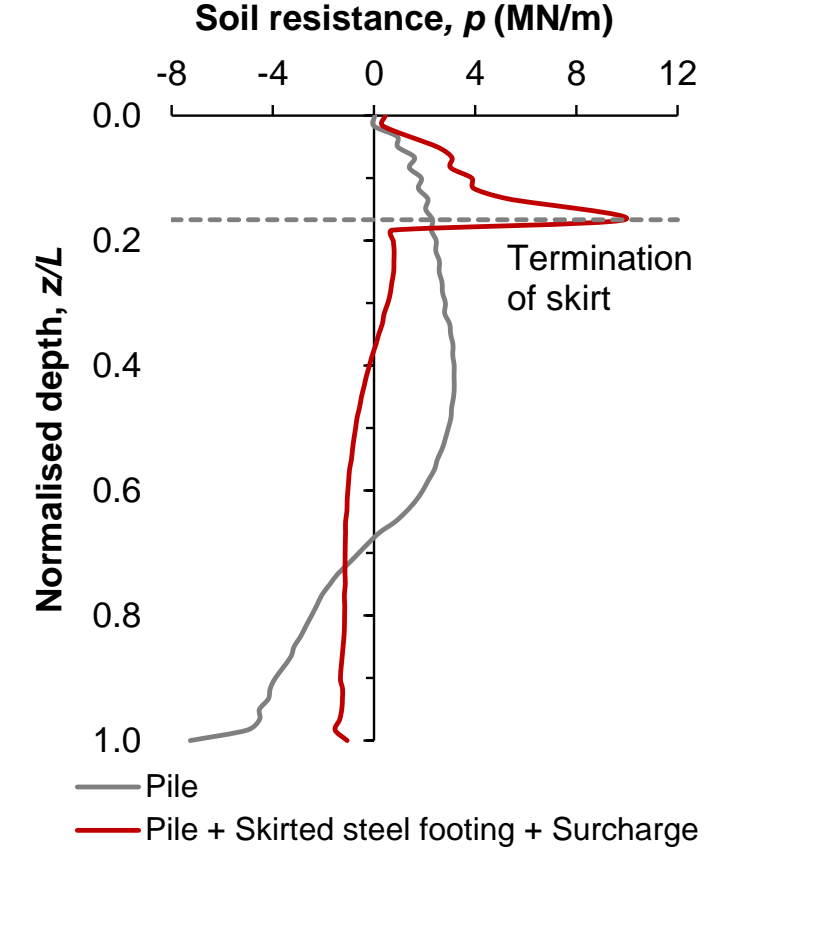

(2n)

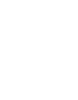

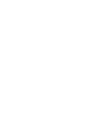
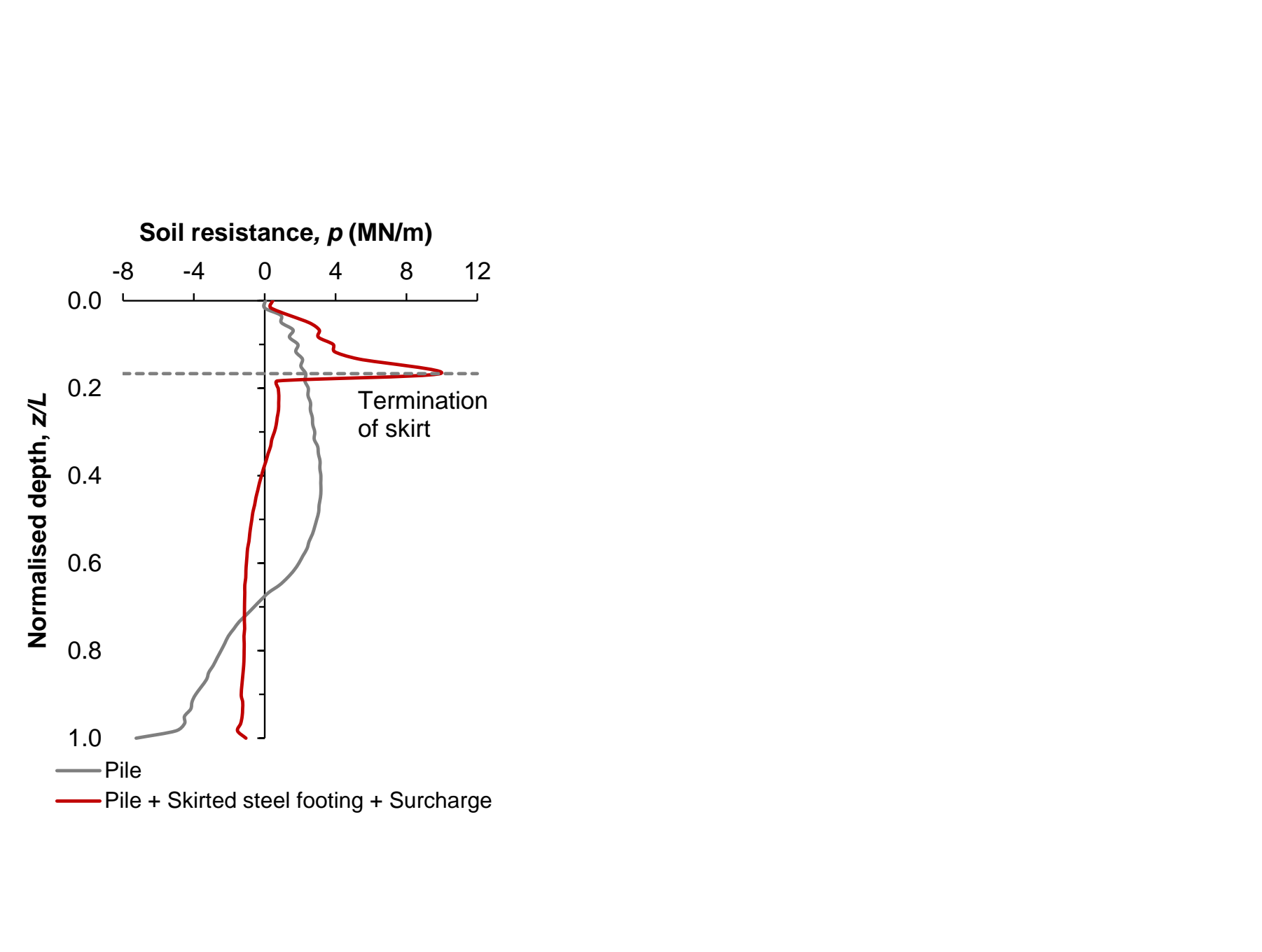


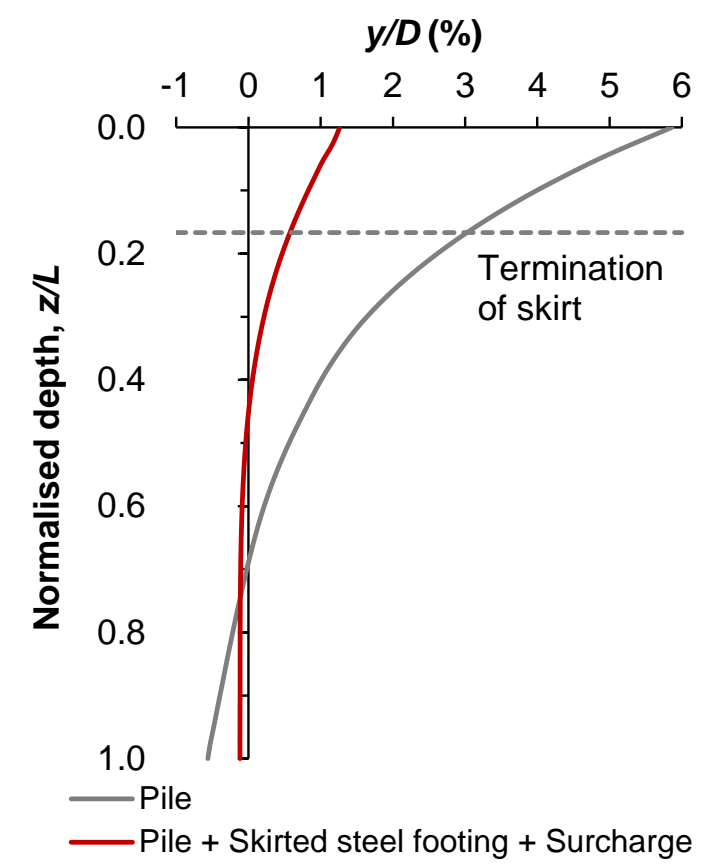

Figure 11b

Figure 11b

.

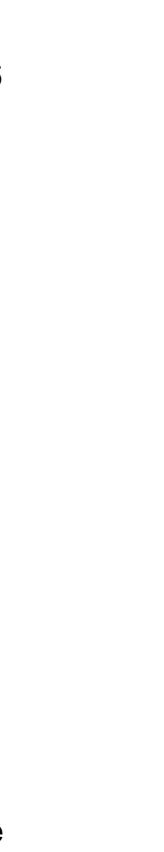




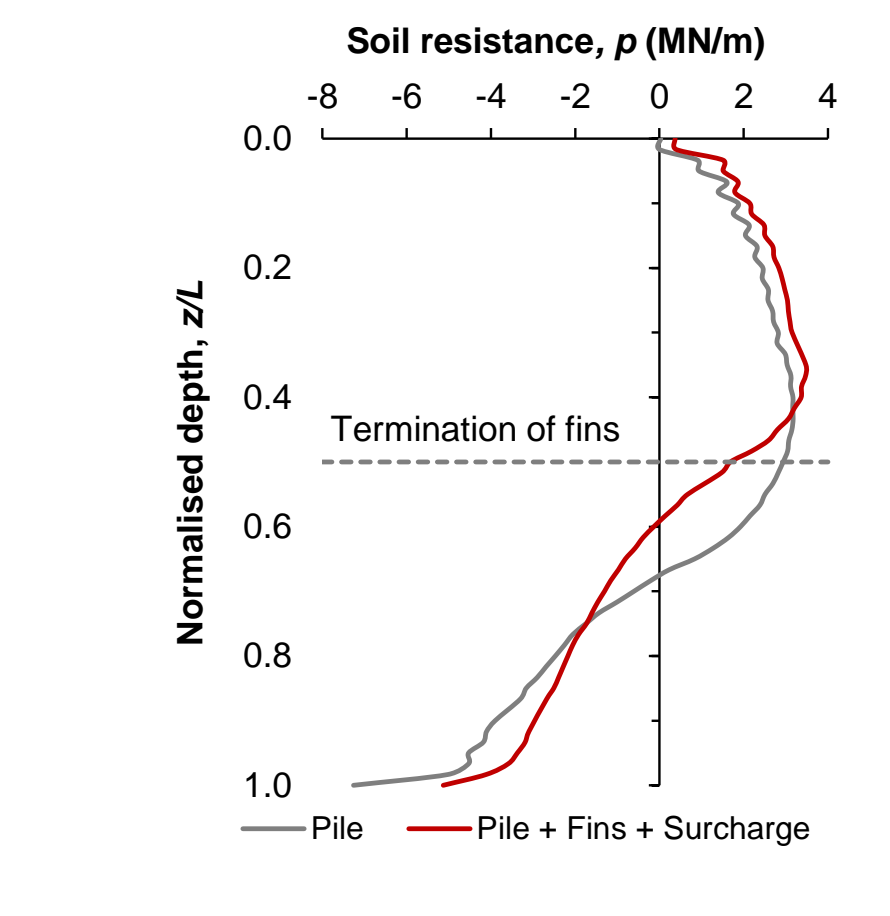

Figure $12 a$

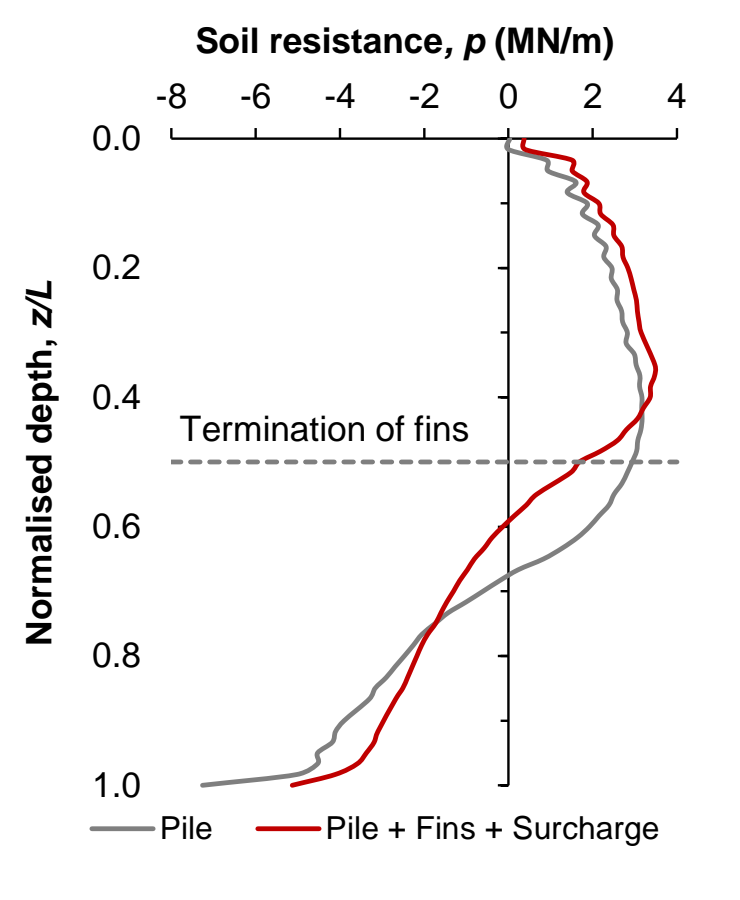

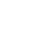
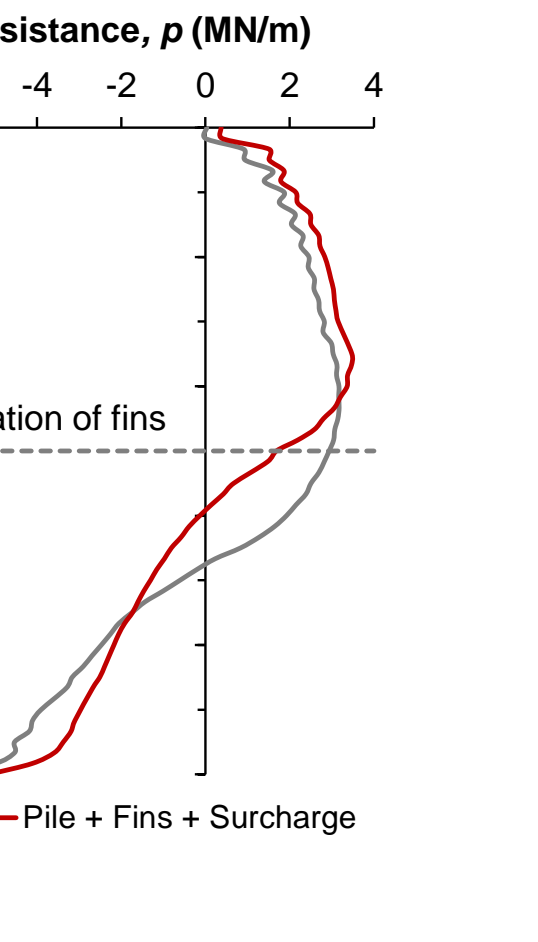


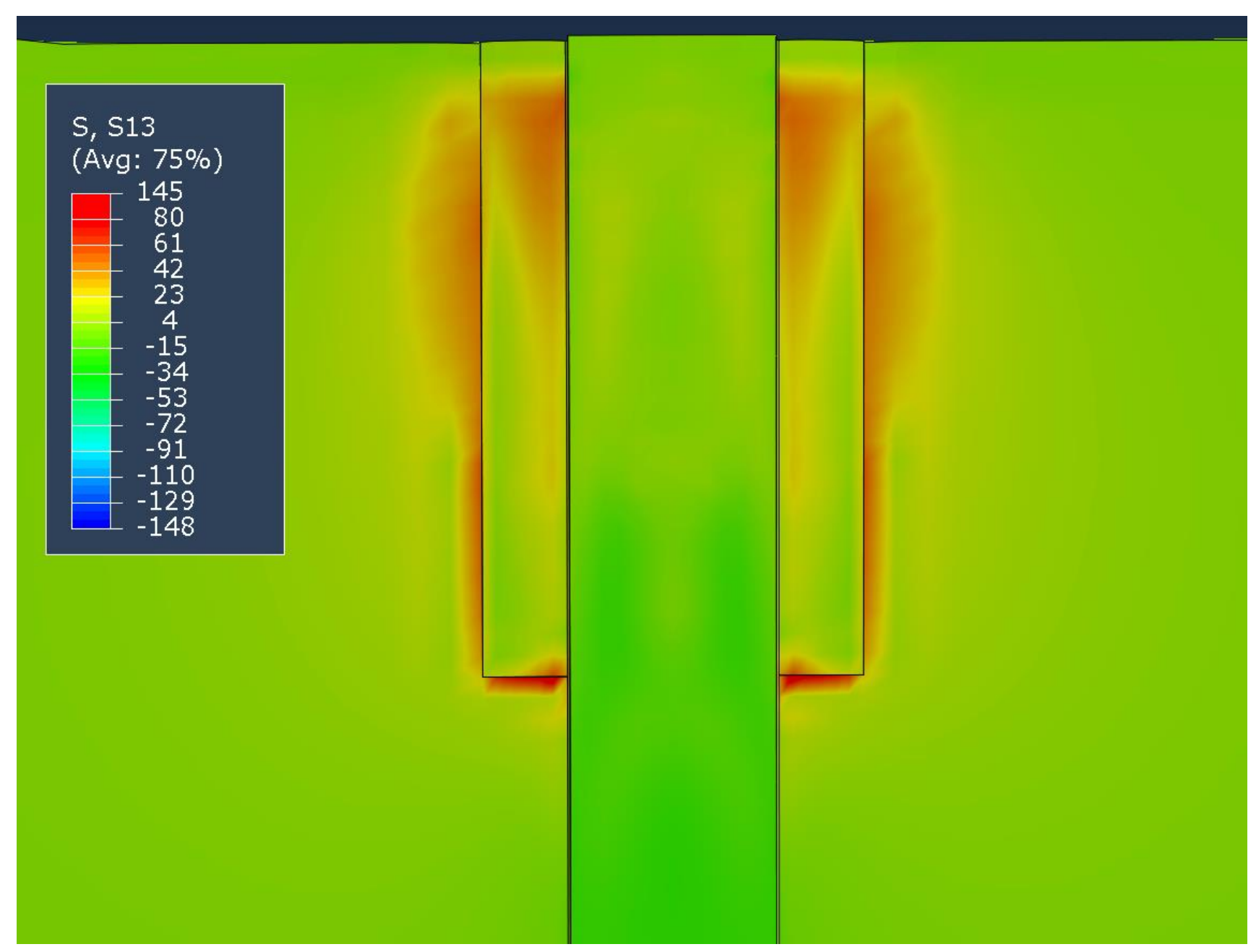


Figure 14a Bending moment $(\mathrm{MNm})$
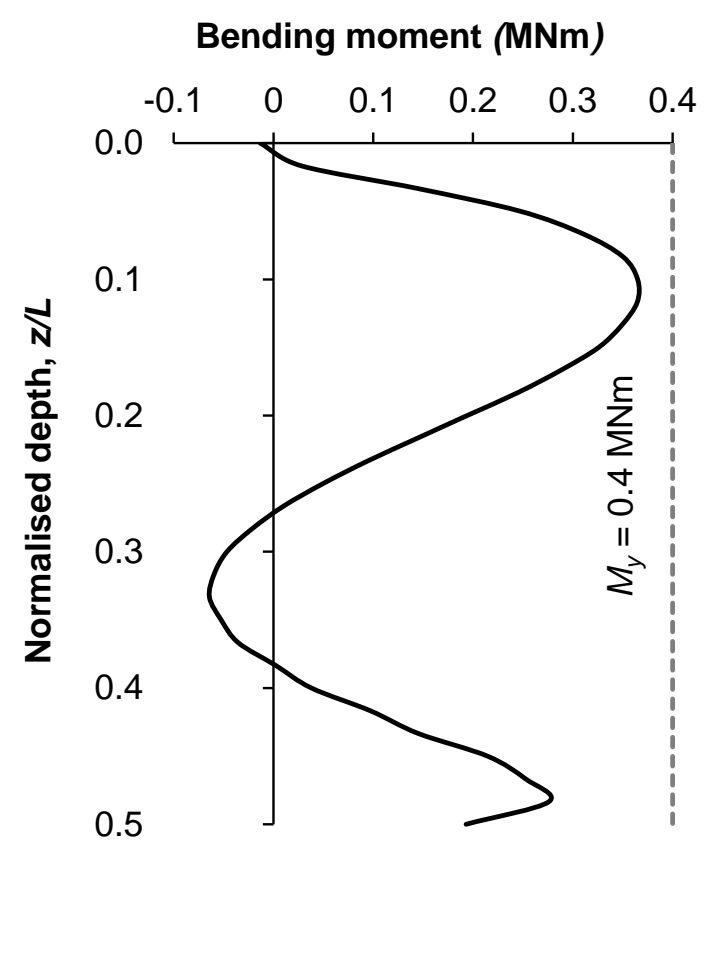

.
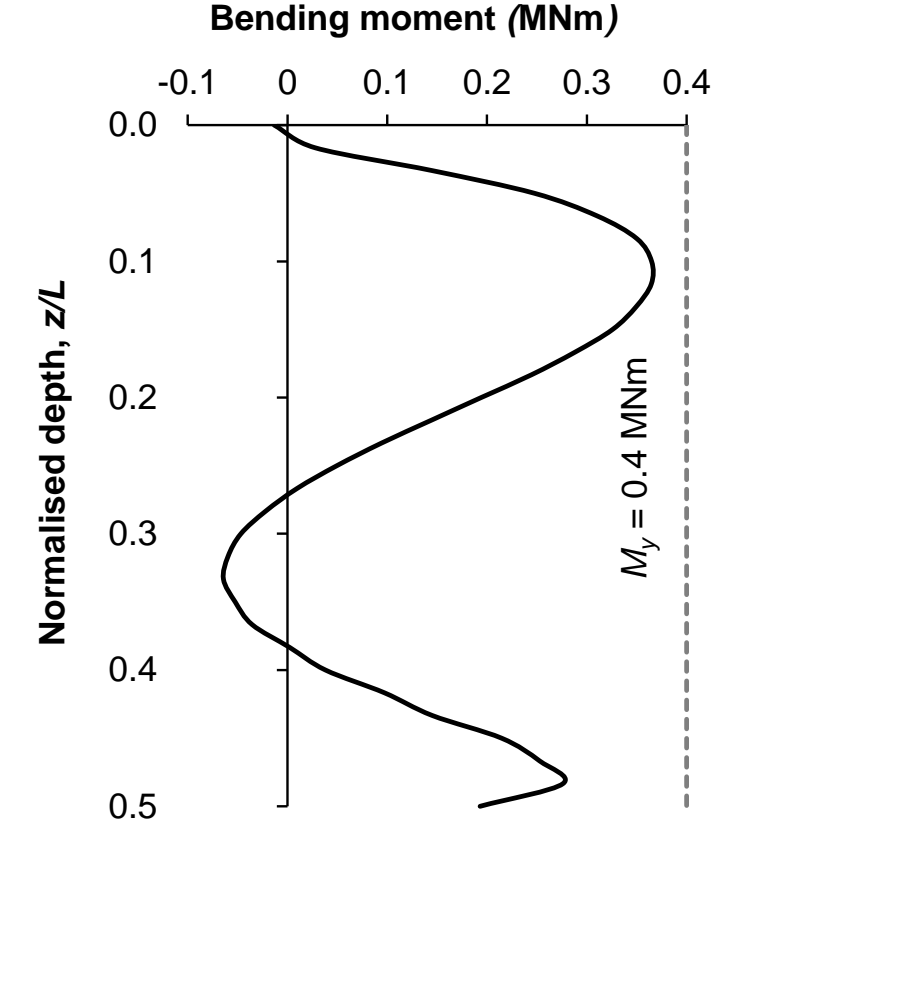


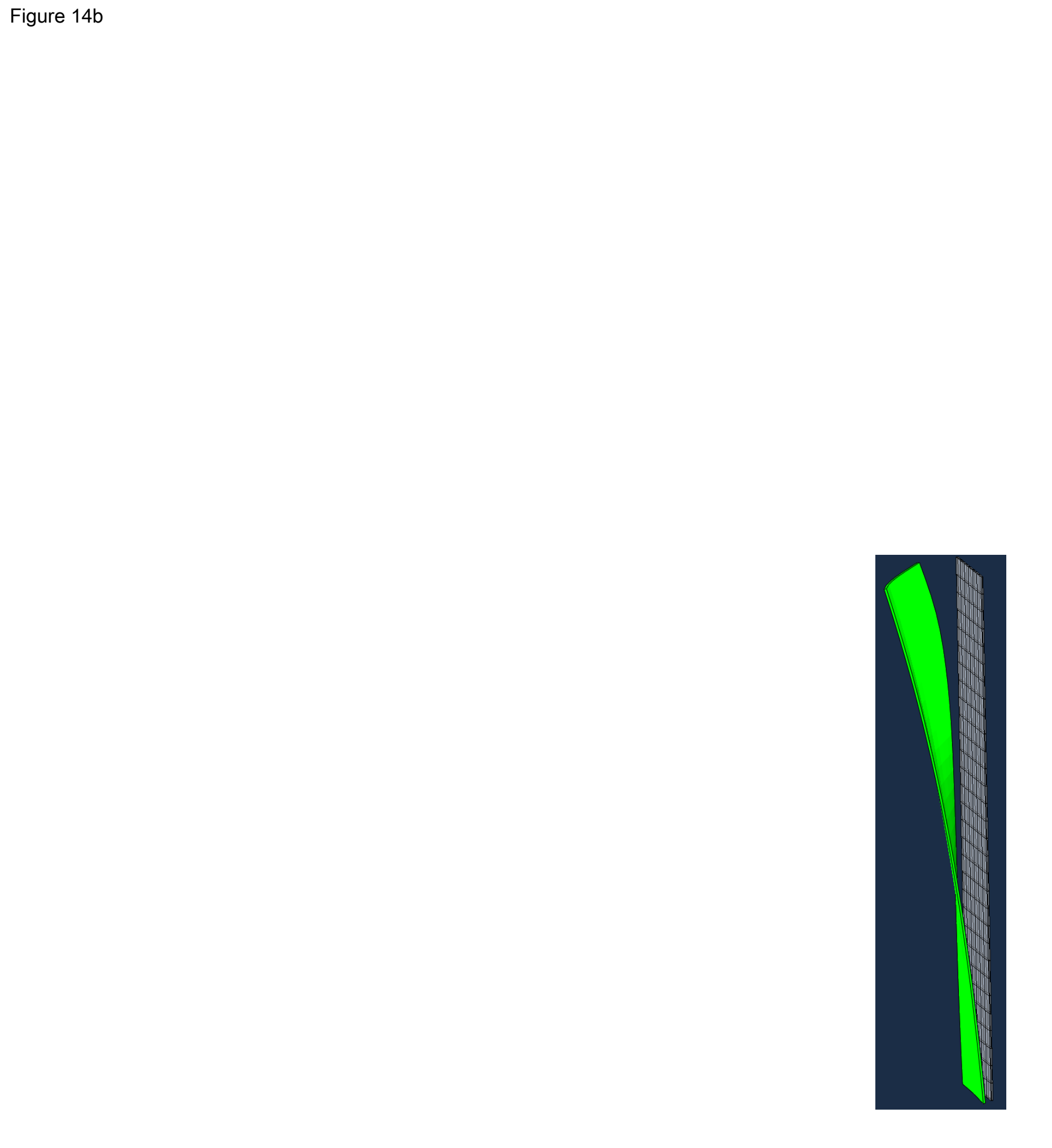

Figure 14

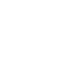
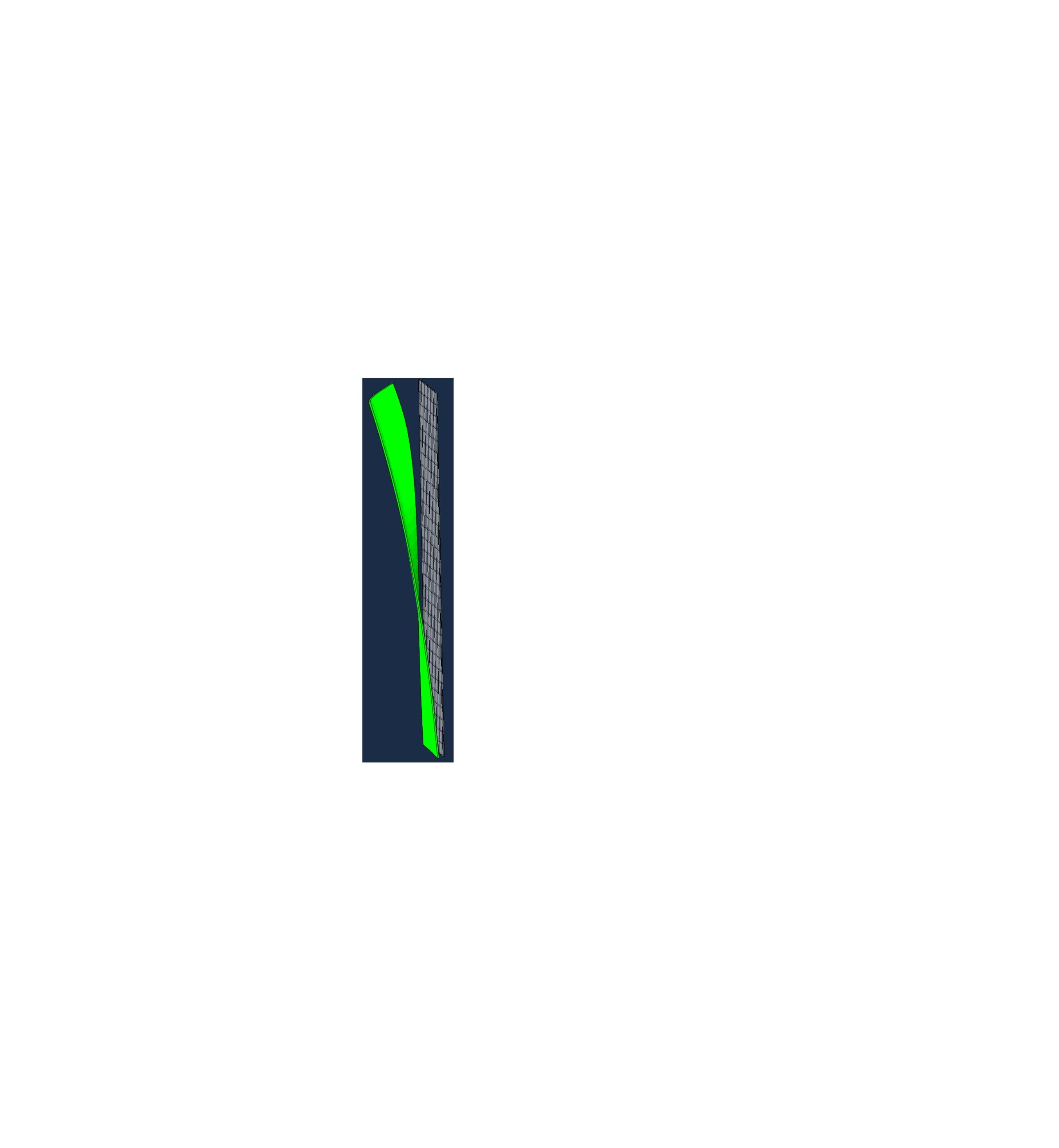


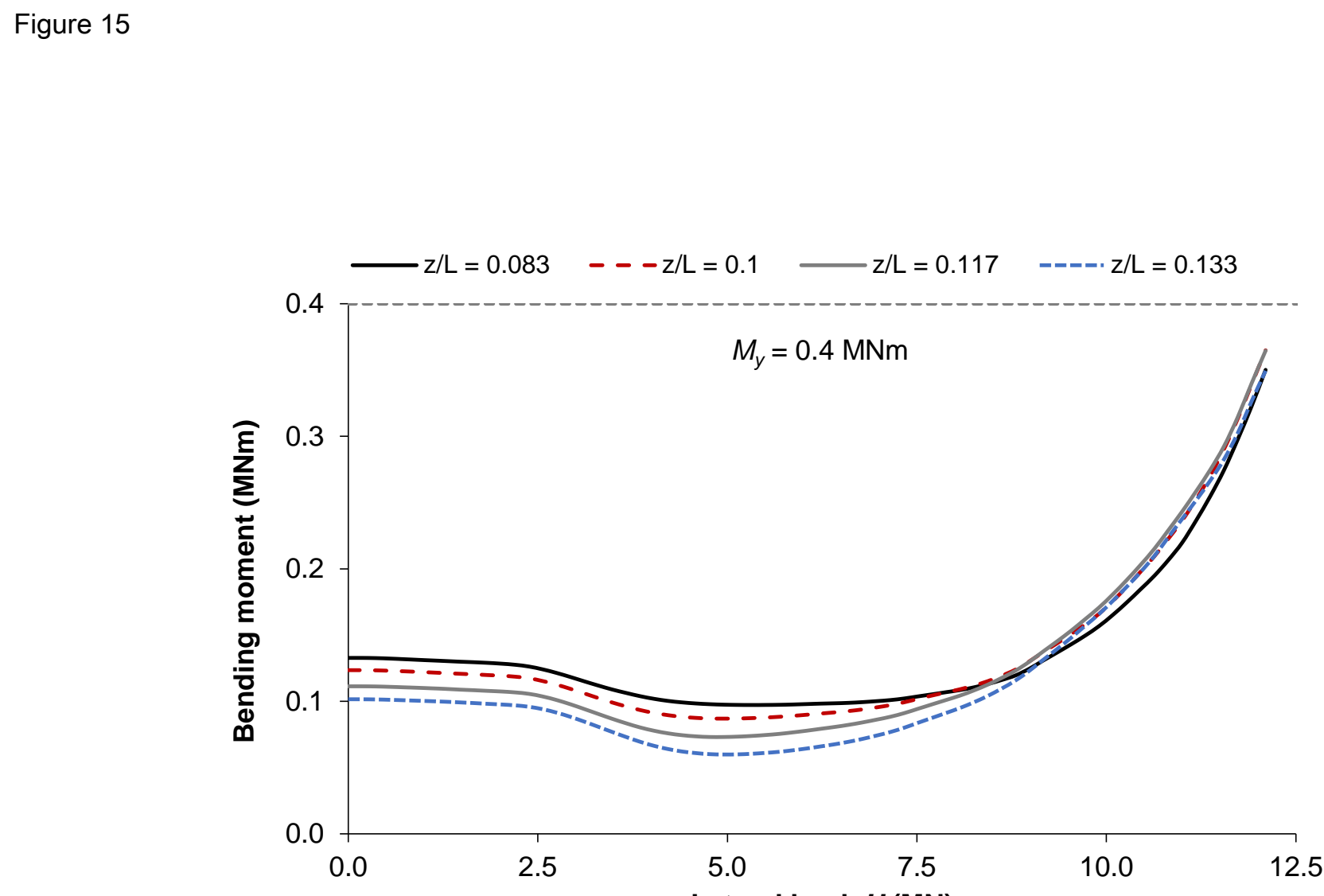

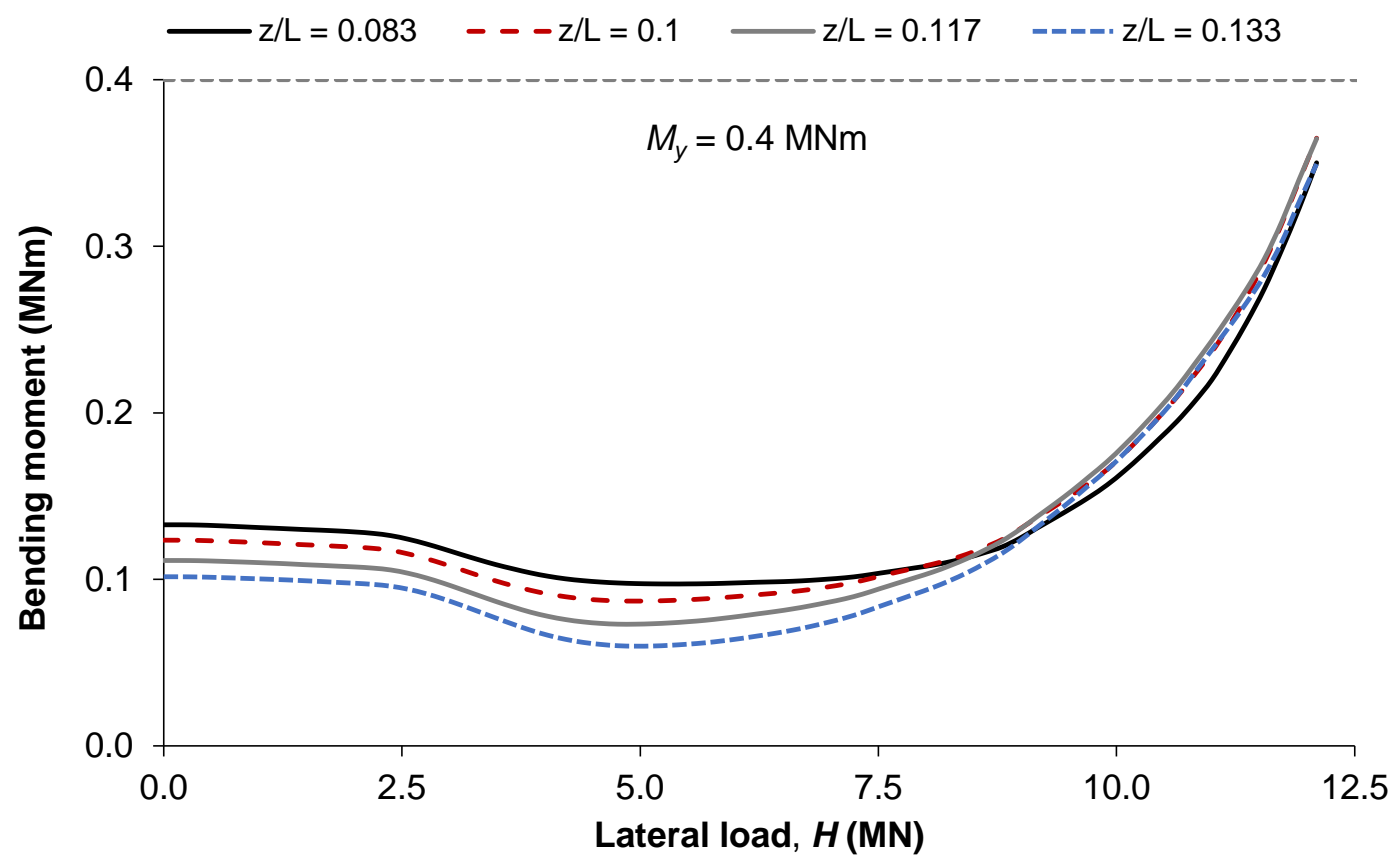

\section{Lateral load, $\boldsymbol{H}(\mathrm{MN})$}





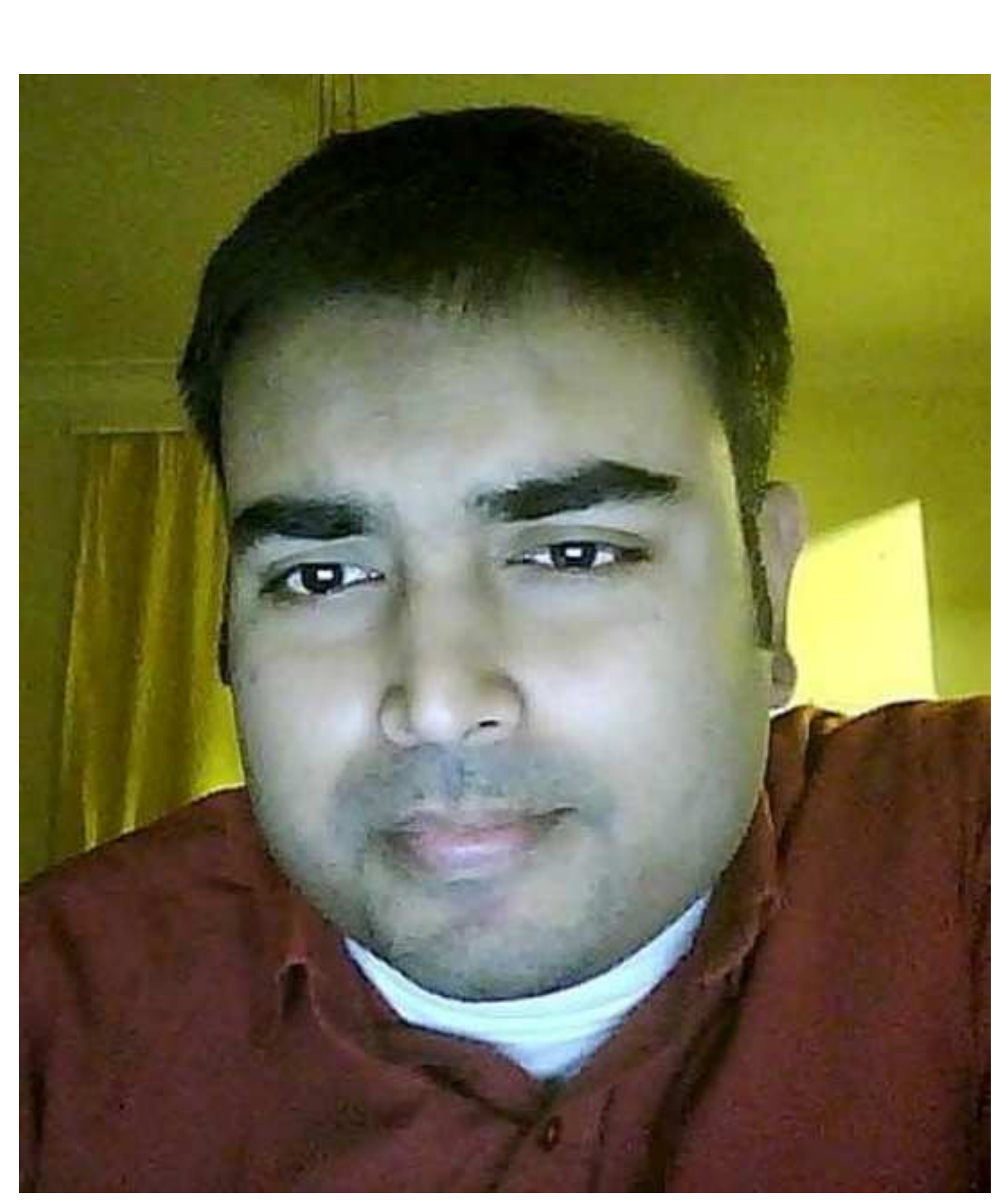

.
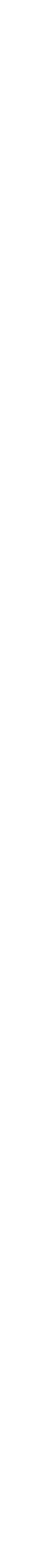


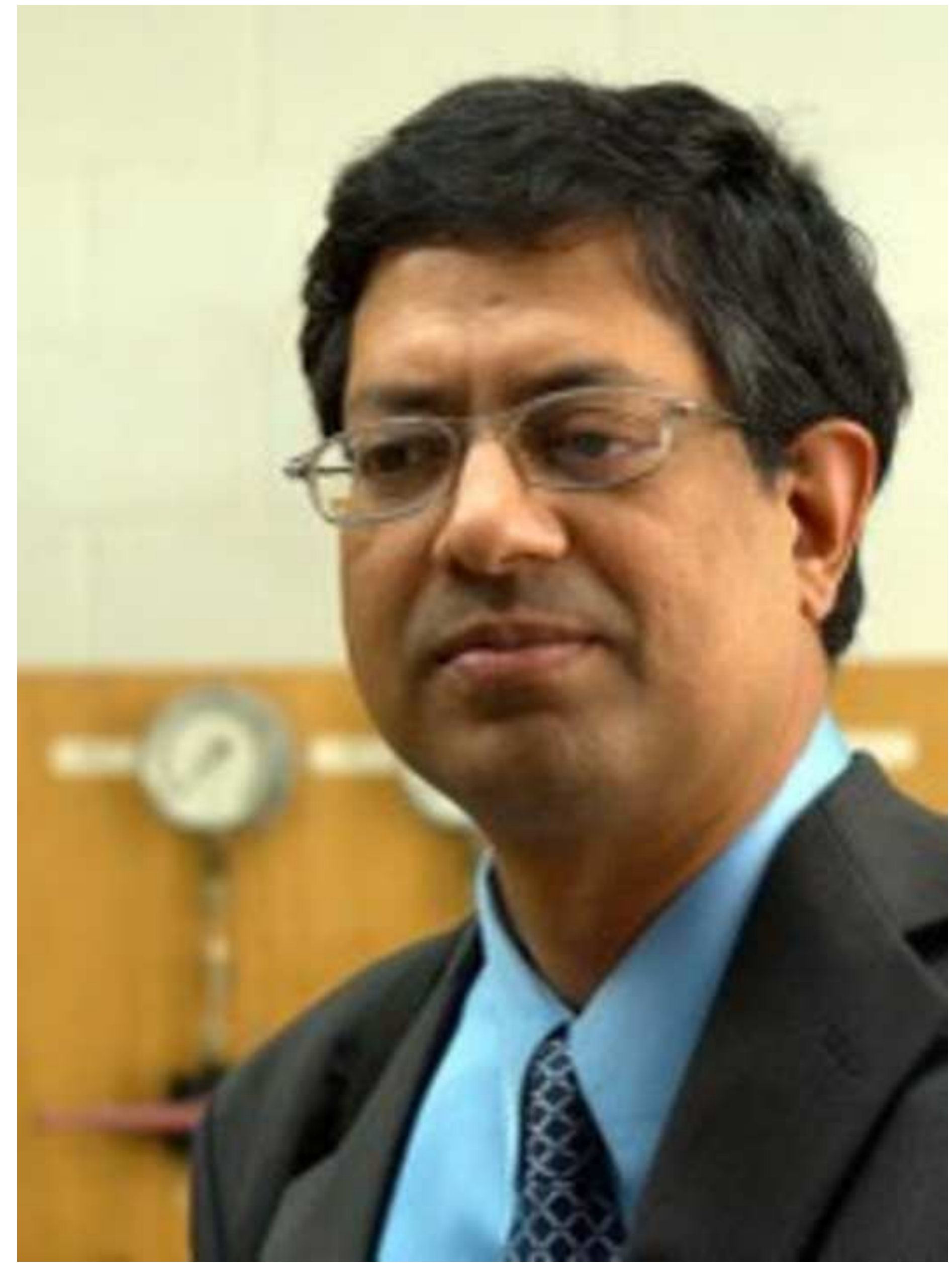

\section{Author 2 Photograph}

